\title{
EXPLORING THE LIVES OF INDIVIDUALS WITH A MENTAL ILLNESS LIVING IN A RESIDENTIAL CARE FACILITY: A QUALITATIVE STUDY
}

\author{
A Thesis presented to \\ The Faculty of the Graduate School \\ At the University of Missouri-Columbia
}

In Partial Fulfillment

Of the Requirements for the Degree

Master of Science

By

\section{RENEE DESNEIGE CHRISTENSEN}

Dr. Benyamin Schwarz, Thesis Supervisor

MAY 2014 
The undersigned, appointed by the dean of the Graduate School, have examined the thesis entitled

EXPLORING THE LIVES OF INDIVIDUALS WITH A MENTAL ILLNESS LIVING IN A RESIDENTIAL CARE FACILITY: A QUALITATIVE STUDY

presented by Renee Christensen, a candidate for the degree of Master of Science, and hereby certify that, in their opinion, it is worthy of acceptance.

Professor Benyamin Schwarz

Professor Ruth Tofle

Professor Coleen Galambos

Professor Newton D'Souza 
I dedicate this paper to all those that that doubted my capabilities and attempted to convince me that I was arrogant for attempting this project. It was because of them that I gained the inner strength to show them what it means to have a passion for something then have the courage to achieve it. 


\section{ACKNOWLEDGMENTS}

I would like to thank the faculty and staff of the Department of Architectural Studies at the University of Missouri for providing me with the knowledge and skills required to complete this process. Dr. Benyamin Schwarz, a simple "thank you" does not seem sufficient for the support, guidance, and encouragement you provided throughout my studies. Dr. Ruth Tofle, thank you for being a positive role model and seeing my abilities which I had not yet realized. Dr. Newton D'Souza, thank you for challenging me to become an efficient researcher and giving me the tools for achievement. Dr. Colleen Galambos, thank you for mentoring me and encouraging me to incorporate areas of study that I would not have considered on my own.

I would also like to thank my family-parents, children, sisters and brothers, for their unending support and understanding through this difficult but rewarding process. Thank you, my friends for reminding me to stay grounded and Shannon for encouraging my sense of humor in difficult times.

Last, but not least, thank you for all the participants in this study for sharing insights into their lives and reminding me of the importance of this project. 


\section{TABLE OF CONTENTS}

Acknowledgement Page................................................................

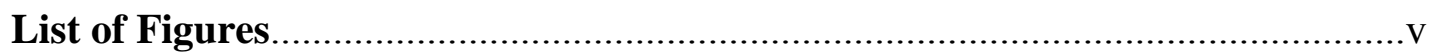

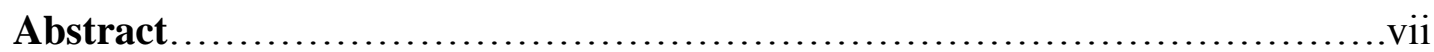

Chapter One: Introduction ..................................................

Statement of the Problem.....................................................

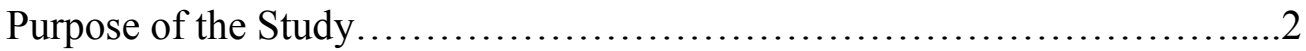

Research Questions.................................................

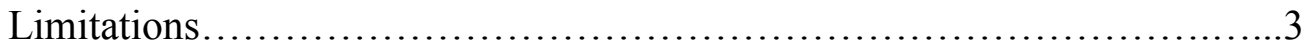

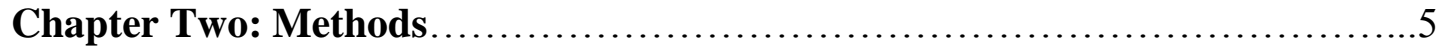

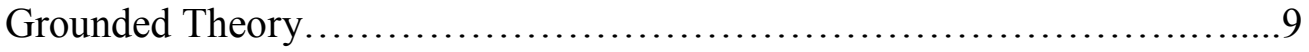

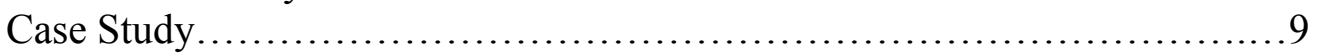

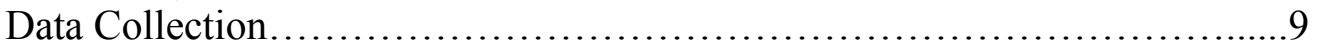

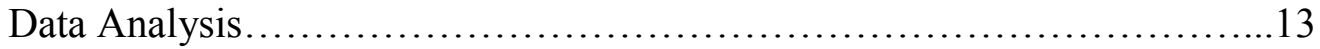

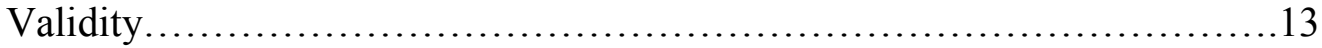

Chapter Three: Conceptual Framework.....................................15

Normalization........................................................ 16

Social Role Valorisation............................................. 17

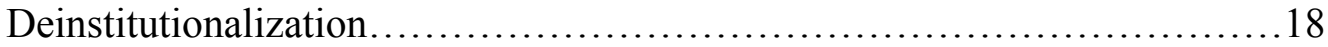

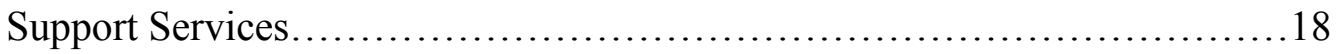

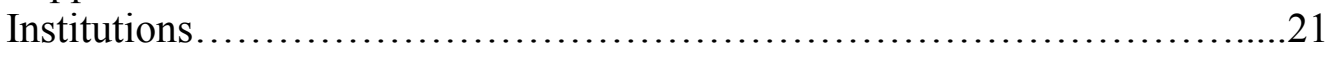

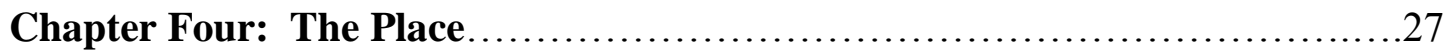

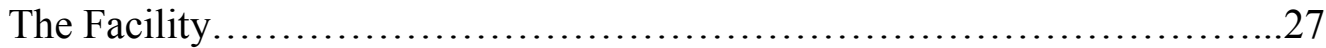

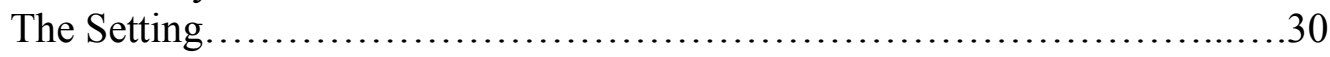

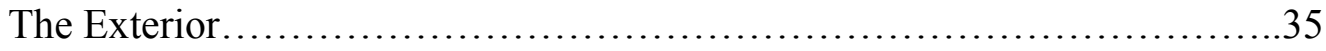

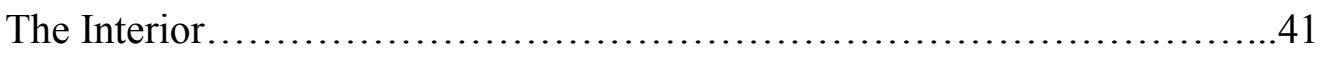

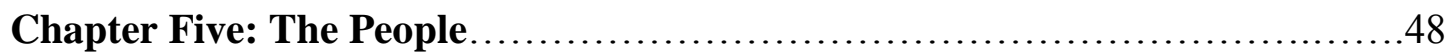

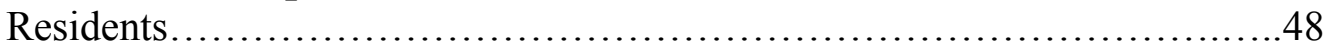

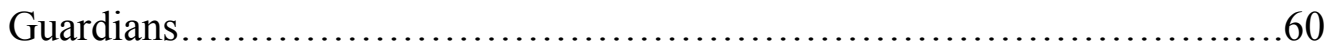

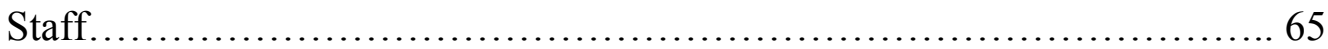

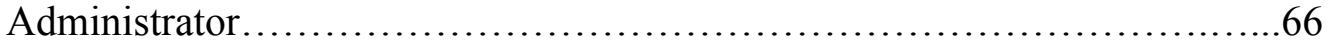

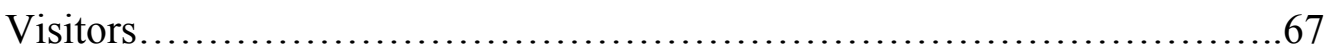

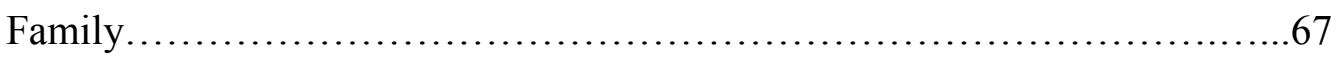

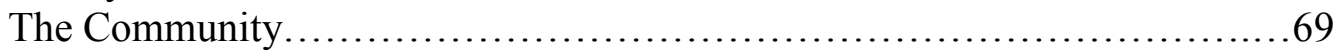




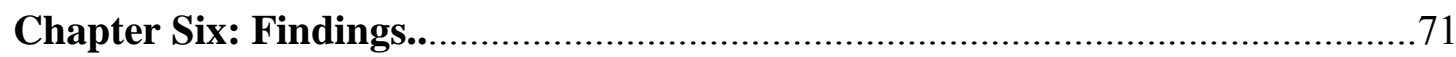

Chapter Seven: Discussion............................................ 75

The Built Environment................................................. 78

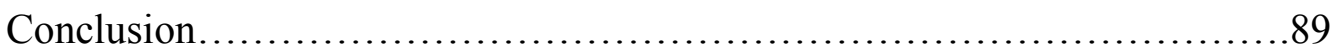

Exhibits.................................................................

References.........................................................97 


\section{LIST OF FIGURES}

Figure 1. Fairfield State Hospital, Connecticut............................................20

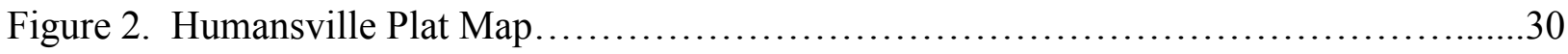

Figure 3. Lakeshores Residential Care Facility Property Lines.................................33

Figure 4. Lakeshores Residential Care Facility Engineering Drawing...........................34

Figure 5. Lakeshores Residential Care Facility from the West................................35

Figure 6. Lakeshores Residential Care Facility from the Northwest...........................35

Figure 7. Lakeshores Residential Care Facility North Wing....................................37

Figure 8. Lakeshores Residential Care Facility Main Entrance at North end.....................38

Figure 9. Lakeshores Residential Care Facility South side....................................39

Figure 10. Lakeshores Residential Care Facility North side..................................39

Figure 11. Lakeshores Residential Care Facility East side (rear).............................40

Figure 12. Lakeshores Residential Care Facility Concrete Building used for Apartments.........40

Figure 13. Lakeshores Residential Care Facility Kitchen....................................41

Figure 14. Lakeshores Residential Care Facility First Floor Corridor............................41

Figure 15. Lakeshores Residential Care Facility First Floor Corridor.........................41

Figure 16. Lakeshores RCF Private Bathroom...........................................42

Figure 17. Lakeshores Residential Care Facility First Floor Corridors with Terazzo Floors.......43

Figure 18. Lakeshores Residential Care Facility First Floor Corridors with Terazzo Floors.......43

Figure 19. Lakeshores Residential Care Facility Octogonal Tiles in Operating Room ...........43

Figure 20. Lakeshores Residential Care Facility Skylight in Third Floor Operating Room.......44

Figure 21. Lakeshores Residential Care Facility Skylight in Third Floor Operating Room.......44

Figure 22. Lakeshores Residential Care Facility Skylight in Third Floor Operating Room......44 
Figure 23. Lakeshores Residential Care Facility Stairwell..............................44

Figure 24. Lakeshores Residential Care Facility Boatwick Elevator.......................44

Figure 25. Lakeshores Residential Care Facility Coal Furnace..........................45

Figure 26. Lakeshores Residential Care Facility Opening in Basement for Coal..............45

Figure 27. Cedar Ridge Apartments, El Dorado Springs Missouri..........................88

Figure 28. Cedar Ridge Apartments, El Dorado Springs Missouri........................88 


\section{EXPLORING THE LIVES OF INDIVIDUALS WITH A MENTAL ILLNESS \\ LIVING IN A RESIDENTIAL CARE FACILITY: A QUALITATIVE STUDY}

Renee Desneige Christensen

Dr. Benyamin Schwarz, Thesis Supervisor

ABSTRACT

Since deinstitutionalization began in the 1950's hundreds of thousands of individuals with a Severe and Persistent Mental Illness were forced out onto the streets. While society may have seen deinstitutionalization as a positive direction for society, the outcome of this grand plan is obscure because the plan had no provision for new living environments for this population.

In this qualitative study I interviewed residents living in a RCF, their guardians, the Administrator, and staff members of the facility in an effort to understand the daily lives of the residents living within the confines of a RCF.

The findings from this study illuminated the daily struggles of individuals with a mental illness and the substantial effect of the interaction between their social and physical environments and recommends further thinking and research on the possibility creating specialized environments for individuals with a mental illness based on a social ecological model. 


\section{CHAPTER ONE Introduction}

Since deinstitutionalization began in the 1950's hundreds of thousands of individuals with a Severe and Persistent Mental Illness were forced out onto the streets. Once a refuge from the unrelenting demands of a rapidly changing and complex world, the shelter sought by millions of people for more than a century would no longer be available. While society may have seen deinstitutionalization as a positive direction for society, the outcome of this grand plan is obscure because the plan had no provision for new living environments for this population.

Although not all individuals who develop a mental illness will become incapacitated to the point where they are unable to care for themselves, some will require assistance with day-to-day living activities. Those individuals who are unable to live independently often live in some type of facility at some point in their lives. This study is an attempt to understand the day-to-day experience of individuals living in a Residential Care Facility (RCF).

\section{$\underline{\text { Statement of Problem }}$}

Little is known about the daily lives of individuals living in a RCF. There have been minimal efforts to understand their daily lives and the substantial effect of the interaction between the individuals and their environment. There continues to be insufficient understanding of how the physical and social environment is responding to the needs of this vulnerable population.

Thomas Markus wrote "without intention there is no artistic form, and without artistic form there is no architecture-the link between function and form is internal to the work of architecture and is also immutable; it hinges on the intention of the creator" (1993). The perpetuation of poor design of long-term care facilities for the mentally ill is the result of a lack of understanding 
regarding the specific housing needs of this population. Without research to inform design, individuals with a mental illness are forced to live in institutional settings and conform their behavior to an environment that does not meet their needs.

\section{Purpose of Study}

Jaber Gubrium (1975) conducted an ethnographic study which examined the social organization of care in a single nursing home in his landmark book Living and Dying in Murray Manor. In his effort to bring the "complicated meanings of living and dying in an institution" to light through the participants perspectives he was able to document how caregiving was actually done and received. In comparison, research examining the lives of individuals living in a RCF is meager. Little is known about the how individuals living in an RCF are managing their daytoday-activities and how their basic needs for food clothing and shelter are being met.

The purpose of this study is to increase the understanding of the unique social organization of individuals living in an RCF. This study inquired into the daily routines of participantsresidents, guardians, RCF staff members, administrators, family and visitors in a single RCF in rural Midwest United States in an effort to gain insight about how these individuals are managing their daily lives within the confines of a RCF.

\section{$\underline{\text { Research Questions }}$}

All the understanding I had about theories of normalization, informed design of treatment centers, the focus on designated areas for specialized behavior and the consideration of architecture as a participant in the treatment process raised questions about current trends in providing housing and treatment in long-term care facilities for the mentally ill. I wondered how facilities, specifically designed for purposes other than housing individuals with a mental illness, have been converted with only minor structural renovations are meeting the needs of this 
population. I wondered why an enormous amount of consideration was given to the treatment and living accommodations of individuals with a mental illness in the nineteenth century but appears to not be an concern in the twenty-first century.

The goal of this research is to understand the daily life of residents who live in Residential Care Facilities. This research will focus on the social and built environment in which they live and the ways in which that environment affects their daily lives.

My research questions revolved around this unique situation where individuals with a mental illness are involved in developing a unique world in which each participant struggles to negotiate their roles, develop goals, and strive to get their needs met within the specified setting. This study specifically asks:

1. Who are the individuals living in Residential Care Facilities (RCFs)?

2. What is the everyday life like for these individuals?

3. How do staff members, the Administrator, guardians, and program representatives view their role in the lives of the residents?

4. What is the interaction between the residents and the physical environment?

5. What are the architectural elements that either assist or impede in the goals of the participants.

\section{Limitations of Research}

The project is not a survey of statistics about the residents in RCF's nor does it address philosophical issues such as moral treatment, freedom and liberty at depth. I have addressed those issues in other projects (Christensen, 2009). Questions regarding housing options for the mentally ill based on service availability have also been addressed elsewhere (Christensen, 2011 and Christensen, 2012) I have also argued for the preservation of the asylums based on its 
contribution to our cultural heritage-the remaining structures serve not as a place of celebration but as a reminder from where our society has evolved (Christensen, 2010). 


\section{CHAPTER TWO \\ Methods}

German philosopher Edmund Husserl's (1899-1938) most basic philosophical assumption was that "we can only know what we experience by attending to perceptions and meanings that awaken our conscious awareness" (Patton, 2001). Another basic tenet to the phenomenological approach refers to the structure and essence of experience of the phenomenon. Patton states the essences are "the core meanings mutually understood through a phenomenon commonly experienced" (Patton, 2001). Nesbitt considers the use of phenomenology in architecture as a "renewed interest in its sensuous qualities of materials, light and color, and in the symbolic tactile significance of the joint" (1996). Other phenomenologists (Hans-George Gadamer, Alberto Pérez-Gómez, Juhani Pallasmaa) continued to elaborate on the concept of dwelling and the representational, symbolic means to achieve it.

J. Douglas Porteous adds complexity to the study of man's relationship with the environment by using a transactional model to describe man's relationship with his environment. He focuses on a behavioral component of the relationship and states

As living individuals...we are compelled by circumstance to make operational distinctions between the organism, its acts, and the environment in which these acts take place. Inability to distinguish one's self from one's environment is an indicator of mental disturbance. Psychiatric observations have shown that even normal individuals may suffer anxieties about losing the ability to distinguish between themselves and their environment...from an egocentric point of view, the distinctions between self and the environment are crucial. Man is not simply a found object in the environment but, like the beaver and the roots of a tree, is capable of influencing or even transforming his environment (Porteous, 1977). 
Porteous offers Environmental Possibilism to support his ideas regarding the consideration of the environment as medium by which man is presented with opportunities. These opportunities may be realized or they may not; the important factor is the choice and effort of man (1977).

While Porteous was working in England, Eco in Italy, Anselm Strauss's Chicago School heritage was informing the way he thought about human action and agency. Kathy Charmaz (2006) says "Strauss viewed human beings as active agents in their lives and in the worlds rather than as passive recipient...Strauss brought notions of human agency, emergent processes, social and subjective meanings, problem-solving practices, and open-ended study of action into a method for designing research studies". Joining forces with Barney Glaser's analytic skills they were able to develop the method of Grounded Theory. Charmaz notes that Glaser and Strauss joined epistemological (positivism) critique by constructing abstract theoretical explanations of social processes (2006). They revolted against the use of research for the sole purpose of testing a hypothesis, allowed the subject(s) of the research to guide the data-to tell their story from their own point of view while treating the data with an intense systematic analysis. Grounded Theory's systematic analysis helped qualitative researchers overcome relativity and helped establish legitimacy in the scientific community.

The preceding linguists and phenomenologists gave me many ideas to consider as I tried to understand the processes by which residents of an RCF make meaning out of their lives within the confines of the facility. Will these residents convey Heidegger and Norberg-Schulz's concepts of "dwelling”, Porteous' opportunities, or the human agency of Strauss? Do they interpret the meaning of architecture in unique ways? I hoped to uncover the "core meanings mutually understood" by the residents and the common understanding they had of their relationship with the building and use that as a foundation for identifying more generalized 
patterns, structures and meanings that emerge from the data which may be unique to the mentally

ill. This has important implications for the future of housing options for individuals with a mental illness-if individuals with a mental illness do not understand "opportunities", feel like they have no personal agency, and convey an absence of a representational or symbolic means to achieve a sense of dwelling within a building, no housing options will be successful.

A qualitative research design lends itself to the understanding of the complexities of the realworld conditions through an inductive approach which emphasizes the development of thick descriptions rather than numbers (Yin, 2011). Furthermore, qualitative studies allow for a better understanding of the particular environments in which the participants act and the influence of this context on their actions. By focusing on the processes by which individuals make meaning out of their lives within the confines of a facility lends itself to a qualitative study. In addition, a qualitative study provides a degree of flexibility as new developments emerge from the data (Maxwell, 2013).

The province of qualitative research is the world of lived experience, for "this is where individual belief and action intersect with culture" (Denzin \& Lincoln, 2011). John Creswell defines qualitative research as beginning with

assumptions and the use of interpretive/theoretical frameworks that inform the study of research problems addressing the meaning individuals or group ascribed to a social or human problem. To study this problem, qualitative researchers use an emerging qualitative approach to inquiry, the collection of data in a natural setting sensitive to the people and places under study, and data analysis that is both inductive and deductive and establishes patterns or themes. The final written report or presentation includes the voices of participants, the reflexivity of the researcher, a complex description and interpretation of the problem, and its contribution to the literature or a call for change (2013).

This definition assisted me with outlining my assumptions, identifying a theoretical framework, developing data collection strategies and data analysis procedures. 
Jaber Gubrium's (1975) landmark ethnographic study published as Living and Dying at Murray Manor highlighted "the complex worlds of caregiving... provides perspectives on the everyday meaning of those world" through his role as a participant observer. He was able to illustrate how the residents of a nursing home develop an organized social entity through the participants' negotiation of roles, goals and needs and invoking rights and duties.

Additionally, Irving Goffman's "immediate object in doing field work... was to try to learn about the social world of the hospital inmate, as this world is subjectively experienced by him...through a critical lens of the discipline of psychiatry and the agencies content with its current practice" (1961). Goffman further contended

it was then....my belief that any group of persons-prisoners, primitives, pilots, or patients-develop a life of their own that becomes meaningful, reasonable, and normal once you get close to it, and that a good way to learn about any of these worlds it to submit oneself in the company of members to the daily round of petting contingencies to which they are subject (1961).

Gubrium and Goffman immersed themselves in the setting as much as possible and used observations as data. Goffman states "I did not employ usual kinds of measurements and controls. I assumed that the role and time required to gather statistical evidence for a few statements would preclude my gathering data on the tissue and fabric of patient life" (1961). He notes his inability to describe the patient's situation "faithfully" as a limitation (Goffman, 1961). In spite of limitations he was able to identify common themes in his data, such as the formation of a personal identity and techniques individuals use to control the information they present to others, how stigmatization requires a social construct of deviancy from the norm, constructed his category of mortification, and developed a definition of "institution" which researchers rely on to this date (Goffman, $1961 \&$ 1963). I believe Grounded Theory methods overcome Goffman's "limitation" regarding his inability to "faithfully" describe the patient's situation through the use 
of multiple sources of data. For example, interviews allow the researcher to wrestle with and refine observations.

\section{Grounded Theory}

Kathy Charmaz notes "simply stated grounded theory methods consist of systematic, yet flexible guidelines for collecting and analyzing qualitative data to construct theories "grounded in the data themselves" (2006). This approach requires the researcher's perceptions, the research questions, the sources and types of data all constantly challenge and adjust each other. This requires a minimization of pre-conceived notions and theories. In lieu of beginning with a hypothesis the researcher must keep her "eyes open and look carefully at individual cases-not in the hope of proving anything, but rather in the hope of learning something" (Eysenck, 1976 as cited in Flyvbjerg, 2011). This description fit well into my approach for this study. This study did not attempt to verify or falsify a pre-existing hypothesis but, instead, was a dynamic and interactive process of forming a working hypothesis based on multiple forms of data.

\section{$\underline{\text { Case Study }}$}

A case study was appropriate for this study due to the focus on an in-depth analysis, which contains more "detail, richness, completeness, and variance" (Flyvbjerg, 2011). In addition, an assisted living facility is a setting that has specific, concrete, environmental boundaries which constitutes an individual unit. This individual unit represents the context in which many individuals live their daily lives.

However, in order to achieve a rich description of the case, data collection must draw on multiple sources of information such as direct observations, interviews with a variety of participants, and an analysis of photographs, documents, and archival records (Yin, 1994). 
Von Eckartsberg (1998) speaks of four steps in the process of establishing a clear set of research procedures and techniques

(1) identifying the phenomenon in which the phenomenologist is interested:

(2) gathering descriptive account from respondents regarding their experience of the phenomenon; (3) carefully studying the respondents' accounts with the aim of identifying any underlying commonalities and patterns; and (4) presenting results, both to the study respondents (in the form of a "debriefing" about the study in ordinary language) and to fellow researchers (in the form of scholarly presentation).

These four steps guided me through the process of developing the procedures and techniques for this study.

\section{$\underline{\text { Data Collection }}$}

In many qualitative studies researchers collect multiple forms of data and spend considerable amount of time in the setting (Creswell, 2013). This study obtained data through observations of the staff and residents' behaviors and interviews with the RCF staff members, administrator, residents, and their guardians. In addition, I drew upon documentation, archival records and photographs to provide more detail and richness.

People are meaning makers and interviews are the most direct way of accessing their experiences. Richards \& Morse state "researchers should beware of attempting grounded theory research with structure data records, which preemptively limit what they will hear in response to their preconceived questions" (2013). In this study I felt like it was best to begin by allowing the participants of the study to generate the data without any imposed constrictions. I did not want to limit the range of responses through previously developed protocols for interviews or limit observations to identifying specific behaviors. Therefore the interviews and observations were highly unstructured. Follow-up questions were used only to clarify a statement or encourage the participant to provide more information about the statement. 
Creswell (2013) considers observations to be one of the key tools for collecting data in qualitative research. Richards \& Morse (2013) consider observation as the most natural of all the ways of making data. Observations must take place in the subject's venue that surrounds them in everyday life to highlight trends imbedded in the context (Groat \& Wang, 2002). Observations allow the researcher the opportunity to balance the understanding of the phenomenon from the point of view of the participants with an outsider's observations (Groat \& Wang, 2002). As an outsider, the researcher is able to see cultural assumptions, beliefs, values, practices, and behaviors embedded within a cultural group. When the researcher remains open to the phenomenon and allows it to show itself in its fullness and complexity through her own direct involvement and understanding unforeseen meanings and themes could emerge (Seamon, 2000).

Reflexivity allows the researcher to make transparent preconceived notions and biases regarding the experience being investigated. In Goffman's studies he acknowledges "no great respect for the discipline of psychiatry nor for the agencies content with its current practices" in his introduction (1961).

Glaser and Strauss refer to their method of data analysis as a "constant comparison." (Charmaz, 2006). Charmaz states "The first analytic turn in our grounded theory journey brings us to coding.... (and) requires us to stop and ask analytic questions of the data we have gathered" (2006). All data (observations, field notes, interviews, etc.) was coded. Johnny Saldaña defines a code as "a word or short phrase that symbolically assigns a summative, salient, essencecapturing, and/or evocative attribute for a portion of the language-based or visual data" (2013). Charmaz (2006) describes coding as the "critical link" between data collection and explanation of meaning." The participants' statements, observations, field notes, etc. became the data and 
the role of the researcher was to link the statements together with the observations and other data in an effort to understand the process.

\section{Charmaz contends}

theorists background assumptions and disciplinary perspectives alert them to certain possibilities... sensitizing concepts and disciplinary perspectives provide a place to start not end. Grounded theorists use sensitizing concepts as tentative tools for developing their ideas about processes that they define in their data (2006).

Findings in my research required incorporation of extant concepts to assist with understanding the phenomenon of how these individuals make meaning of their situation.

In-depth, open-ended interviews were conducted with as many residents as possible. In order to obtain information that provides detail and richness, open-ended interviews were conducted. The interviews with residents focused on the circumstances that led to the individual's confinement and their continued residency at the assisted living facility. Inquiries attempted to illicit information regarding their initial placement and subsequent placements at an assisted living facility and their perceptions about why they continue to live in an assisted living facility.

In-depth, open-ended interviews with RCF staff members, Administrator and guardians attempted to obtain information about their perceptions of the role they play in the daily lives of the residents and to identify the facility's program goals.

Observations recorded the variety of behaviors residents engage in on a daily basis. The focus of the observations was on the daily activities of the residents as they went through their day. Observations recorded not only the residents individually, but also their interactions with each other and the staff.

A rich description of the environmental attributes was included in an attempt to highlight the understanding of the role that architecture plays in the daily lives of individuals. Floor plans, 
photographs, and descriptions of architecural features such as lighting, temperature, furniture arrangement, and space configuration were included.

\section{$\underline{\text { Data Analysis }}$}

All interviews were transcribed and coded. Charmaz (2001) describes coding as a critical link between data collection and explanation of meaning. An open-coding system was used to capture new insights emerging from the data (Corbin \& Strauss, 2007). Initially, In vivo coding was used to "preserve participant's meanings of their views and actions... and serve as symbolic markers of participants" meanings" (Charmaz, 2006). Substantive categories were then developed, based on the data, to provide descriptions of the participants' concepts and beliefs. Theoretical categories were then developed to organize coded data into a more general or abstract framework.

Observations recorded as field notes were coded similar to interview transcriptions with the exception of an initial attribute coding to provide basic description of the setting, time frame and other similar variables of interest.

Saldaña notes that the "best approach to analyzing visual data is a holistic, interpretive lens guided by intuitive inquiry and strategic questions" (2013). Visual data-drawings, photographs, floor plans, etc. were repeatedly reviewed and analyzed to develop sub-codes for the purpose of allowing a more detailed analysis of the data corpus. An analysis of photographs, floor plans and other physical characteristics of the setting were conducted with a focus on how the participants in this setting interact with each other and use the spaces within the facility.

$\underline{\text { Validity }}$

Validity was obtained through triangulation-obtaining multiple sources of data collection. Additionally, reflexivity was obtained through a transparency of the "researcher's 
epistemological assumptions, their influence on the framing of the research questions and any changes in perspective that might emerge during the course of the study" (Groat \& Wang, 2002). 


\section{CHAPTER THREE Conceptual Framework}

French philosopher, Michel Foucault, described the system that founded the landmark Hópital Général in Paris, France in the mid 1600's as a system developed for collecting and confining those who could introduce instability into the society. Foucault's criticism of this system was that it was the starting point for which some groups of society exerted power and control over others. The system created a hierarchy among social structures that were reflected in the architecture. Thomas David and Carol Weinstein note that the "design of institutional settings is dominated by programmatic considerations that are in turn shaped by a guiding image of the institution's function" (1987).

Prior to the 1800 's mental illness was considered a spiritual issue and the Protestant Reformers remained the primary influence of Early American society and the care of the mentally ill in private homes reflected the importance they placed on the family system. As the Enlightenment drew near, questions regarding the etiology of mental illness caused a dramatic effect on the treatment of the mentally ill. Early American thinkers believed the family failed to teach the child good moral character and therefore it made sense to them that their embattled community members could best be cared for together in a building that reflected proper values. They intended not only to reform those ignorant of proper moral behavior but also, to set an example for the rest of the community. They not only purchased pre-existing homes, converting them only slightly, but they built new structures which reflected their ideas regarding morality, spirituality and mental illness. 
The medicalization of mental illness during the mid-1800's dramatically changed the face of mental illness in the United States. The Enlightenment ideas that swept across North America brought with it ideas that resulted in the advancement of medicine into an organization and socially powerful profession (Forty, 1986). French physician, Philippe Pinel (1745-1826) was instrumental in the development of a more human approach to the treatment of psychiatric patients. Known today as Moral Treatment, Pinel advocated for a nonviolent and nonmedical treatment for the mentally ill.

\section{$\underline{\text { Normalization }}$}

The principle of normalization was developed in Scandinavia during the 1960's. Swedish activist Bengt Nirje is internationally known for his work in promoting self-determination among people with intellectual disabilities. Critical to the theory of normalization is the inclusion of people with disabilities in all aspects of society-schools, careers, homes, relationships and leisure. Nirje's ideas regarding Community Integration (CI) were the antithesis of the exclusionary practices during the time.

The work of Nirje affected American politics as well. Title VIII of the Civil Rights Act of 1968 is commonly known as the Fair Housing Act and was meant as a follow-up to the Civil Rights Act of 1964. The 1968 act expanded previous acts and prohibited discrimination concerning the sale, rental, and financing of housing based on race, religion, national origin, and since 1974, gender; since 1988, the act protects people with disabilities and families with children.

Government reports from Australia in the 1980's specifically incorporated recommendations of "the rights of people with intellectual handicaps to receive appropriate services, to assert their 
rights to independent living so far as this is possible, and to pursue the principle of normalization."

Normalization has had a significant effect on the way services for people with disabilities have been structured throughout the North America, UK, Europe, Australasia and increasingly, other parts of the world. It has led to a new conceptualisation of disability as not simply being a medical issue (the medical model which saw the person as indistinguishable from the disorder), but as a social situation. It is the environment that must be normalized, not the individual.

The principle was further developed during the 1970's, especially by Wolf Wolfensberger in Canada through the National Institute on Mental Retardation (NIMR).

\section{$\underline{\text { Social Role Valorisation }}$}

Wolfe Wolfensberger coined the term Social Role Valorisation (SRV) to describe his theory about why individuals with disabilities need to participate in socially valuable roles. Much of Wolfensberger's work has been concerned with ideologies, structures and planning patterns of human service systems, especially concerning persons with intellectual disabilities and their families. Joe Osburn describes the goal of SRV as creating or supporting socially valued roles for people in society

because if a person holds valued social roles, that person is highly likely to receive from society those good things in life that are available to that society, and that can be conveyed by it, or at least the opportunities for obtaining these. In other words, all sorts of good things that other people are able to convey are almost automatically apt to be accorded to a person who holds societally valued roles, at least within the resources and norms of his/her society (1998).

Another social movement was also responsible for the future treatment of the mentally ill. The Civil Rights movement during the 1950's and 1960's illuminated prejudicial attitudes not only toward different races but also towards individuals with disabilities. 


\section{Deinstitutionalization}

According to psychiatrist and author Thomas Szasz, deinstitutionalization is the policy and practice of transferring homeless, involuntarily hospitalized mental patients from state mental hospitals into many different kinds of de facto psychiatric institutions funded largely by the federal government (Szasz, 1970).

The deinstitutionalization of the mentally ill began in the United States in the 1950's. During the 1960's the deinstitutionalization movement was formally translated from a philosophy into a tangible social program. The plan was set in motion by the Community Mental Health Act as part of John F. Kennedy's legislation and passed by the U.S. Congress in 1963.

\section{$\underline{\text { Support Services }}$}

Erving Goffman (1971) has noted that "mental patients can find themselves crushed by the weight of a service ideal that eases the life for the rest of us". German sociologist Max Weber described an organization as the formal structure of specialized, interlocked roles, each with a position in the hierarchy of authority and a specific set of duties. An important element within an organization is the mission statement which reflects the organization's values. Those values are then translated into explicit goals whose outcomes are measureable.

Furthermore, Eric Sundstrom contends that the organizations effectiveness, defined as the extent to which an organization efficiently accomplishes its mission while maintaining continued viability, relies heavily upon the effectiveness of the roles played by all users of the structure (1986). For institutions to remain viable they must place order based on a stable category of people, objects and activities, together with a set of rules which govern interactions. 
The program of deinstitutionalization included the development of support services. The support services were to be developed by private organizations with oversight and funding to be provided by the state and federal governments.

Additionally, the plan for deinstitutionalization, Community Mental Health Centers (CMHC's) were developed to provide support for the mentally. CMHC's are organizations that manage and deliver mental health services to a specified geographical area. According to the Centers for Medicare and Medicaid Services, a CMHC is

an entity that meets applicable licensing or certification requirements for CMHCs in the State in which it is located; and must provide all of the following core services to meet the statutory definition of a CMHC. However, effective March 1, 2001, in the case of an entity operating in a State that by law precludes the entity from providing the screening services. The entity may provide for such service by contract with an approved organization or entity (as determined by the Secretary) that, among other things, meets applicable licensure or certification requirements for CMHCs in the State in which it is located. A CMHC may receive Medicare reimbursement for partial hospitalization services only if it demonstrates that it provides such services. The core services include: Outpatient services, including specialized outpatient services for children, the elderly, individuals who are chronically mentally ill, and residents of the CMHC's mental health service area who have been discharged from inpatient treatment at a mental health facility; 24 hour-a-day emergency care services; Day treatment, or other partial hospitalization services, or psychosocial rehabilitation services; and screening for patients being considered for admission to State mental health facilities to determine the appropriateness of such admission. (Centers for Medicare and Medicaid Services, 2013).

Support services through CMHC can range from case managers to therapists to psychiatrists. CMHC's have psychiatrists on staff along with many therapists. Their community support services will often include a case manager. The case managers can help them with a variety of issues from balancing their bank accounts, getting their bills paid, assisting with medical appointments (including transportation arrangements) developing, practicing social skills and managing social interactions assisting them with accessing and maintaining other community services and program (Food Stamps, HUD, Medicaid/Medicare, Social Security, etc.). These 
services are imperative for the success of individuals with a mental illness living independently but less necessary for the individuals living in an RCF because the staff members at the RCF assume the responsibility. The local CMHC also provides psychosocial rehabilitation services PSR. The goals of PSR to restore an individual's ability for independent living, socialization and effective life management. With psychosocial rehabilitation, clients are provided with numerous opportunities for social, recreational and vocational activities. Participants learn and improve skills needed to succeed in these activities (Burrell Behavioral Health, Services, 2013).

In an egalitarian society respect for human dignity demands that basic human needs, such as food, clothing, and shelter be accessible to all people. However, as deinstitutionalization proceeded, little thought was given to housing needs of this fragile population. Perhaps policy makers misunderstood the theory of normalization to mean the mentally ill, mentally retarded or developmentally disabled population would be able to go out into the community, be provided with the basic human needs and live as close to a normal life as possible. Here, the pressure is on the individual to adjust their behavior to meet the needs of society instead of on society to provide all members equal opportunities. Equal opportunities does not mean that everyone is treated the same. It requires an understanding of unique housing needs relative to issues of empowerment of this population.

Thomas Markus, Emeritus Professor of Building Science at the University of Strathclyde (Scotland), architect, designer, teacher and consultant in Europe, Middle East, Africa, Asia and North-America, wrote, in Buildings \& Power: Freedom \& control in the origin of modern building types, "society's ideological expression not only exist in popular discourse; they also appear in material structures" (1993). Chris Dalglish (2005) added that these ideological 
expressions were reflected in architecture and were the beginning of a wider and long-term

process towards change that, once initiated was powerful and inexorable.

$\underline{\text { Institutions }}$

Programmatic considerations were overtly stated and evident in nineteenth century institutional architecture. Theories regarding moral treatment and the curative powers of sculptured landscape guided the design of mental institutions during the nineteenth century. Both the Cottage Plan and Kirkbride's Plan agreed upon the curative powers of the landscape. However, the similarities stopped there.

The Cottage Plan such as those developed by Shepley, Rutan and Coolidge for McLean Hospital in Belmont, Massachusetts provided that institution with an atmosphere of a "prep school or well-endowed college" (Beam, 2001). The buildings were designed in styles that reflected the high culture of the time and were intended to create a residential, rather than an institutional, effect for patients. The buildings were normally two stories tall or less and connected through a series of underground tunnels. Typically an administration building was located at the front of the campus and patient buildings would encircle the campus with communal buildings such as a kitchen, chapel, or auditorium in the center. Markus notes "the focal point of the design is an expression of the social, political and economic values which re then translated into space" (Markus, 1993). The placement of the administration building, kitchen and chapel in the center exemplify the utopian ideas regarding reforming the deviant and dependent in the Jacksonian Era in North America.

The Honorable Mr. Eddy noted, about Fairfield hospital in Connecticut:

the laying of the cornerstone of the building from which will be administered the conduct of an institution for the care....the cure of those unfortunate people whose minds have become deranged with strange fancies and who have lost control over their thoughts and emotions. Here we hope that the pure air and 
sunshine and the cheerful outlook on nature so abundantly available on this beautiful hillside, combined with modern equipment and skillful treatment, may make it possible to restore to mental health many who have been groping in the fogs of despondency or hallucinations, and that at least some of the gloom and suffering may be driven from the mind of the incurable (Fairfield State Hospital, 2013).

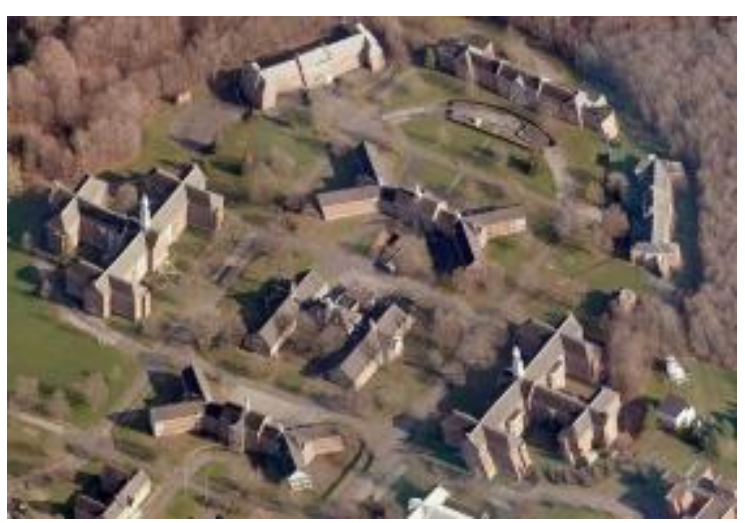

Figure 1. Fairfield State Hospital, Connecticut.

The cottage plan allowed for the segregation of noisy and violent patients. In addition, the noisy and violent patients were situated closer to the administrative staff to allow for closer supervision. The most significant departure from the Kirkbride plan was that it placed the most violent patients closest to the administration, a complete reversal from the Kirkbride plan. In Kirkbride's Plan, the building form itself was meant to have a curative effect: "a special apparatus for the care of lunacy, [whose grounds should be] highly improved and tastefully ornamented" (Yanni, 2007). The idea of institutionalization was thus central to Kirkbride's plan for effectively treating patients with mental illnesses. Utopian ideas regarding reforming the deviant and dependent continues to serve a model for society today.

Today, mental illness is considered treatable, but not preventable or curable. The difficulties that people suffering from mental illness had in the nineteenth century have not disappeared. The medicalization of mental illness has become the predominant focus in psychiatry and the role of architecture has been minimized. 
Institutions are pervasive in our society and institutional values, and, as Robinson notes:

are used in the design of just about every place other than the single family dwelling, including the workplace, schools, commercial buildings, and daycare centers. Part and parcel of the largest sector of or construction industry, instituteional design is reinforced by typical development and financing procedure as well as by law, in the form of things such as zoning and building codes. Characterized by a primacy of economics over human aspiration and need, the institutional approach to design that is taken for granted results from culturally sanctioned values that we do not have to perpetuate (2006).

Nineteenth-century psychiatrists considered the architecture of their hospitals to be one of the most powerful tools in the treatment of the insane and architects struggled to translate the theories of psychiatrists into a design form. The novel building type that emerged was a result of compromises in the "tensions between home and institution, benevolence and surveillance, medical progress and social control, nature and culture" (Yanni, 2007).

The mental institutions of the nineteenth century began with good intentions but over the course of a hundred years social critics began to publicize accounts of severe abuse and neglect. As the twentieth century approached new philosophies emerged which affected the way mental illness was treated. The increase in the medicalization of mental illness led to the discovery of chlorpromazine hydrochloride for the treatment of schizophrenia in the 1950's. Marketed in the United States under the name Thorazine, it has been described as the single greatest advance in psychiatric care, dramatically improving the prognosis of patients in psychiatric hospitals worldwide The availability of antipsychotic drugs dramatically curtailed the use of other therapies such as electroconvulsive therapy and psychosurgery and was one of the driving forces behind the deinstitutionalization movement.

While society may have seen deinstitutionalization as a positive direction for society, the outcome of this grand plan is obscure. Deinstitutionalization resulted in the closure of hundreds of large, state-run asylums for the mentally ill, mentally retarded or developmentally disabled. 
Once a refuge from the unrelenting demands of a rapidly changing and complex world, the shelter sought by millions of people for more than a century would no longer be available. The program of deinstitutionalization could have led to more opportunities for a variety of living situations for the mentally ill. However, the plan made no provision for the construction of any type of living facilities for individuals with mental illness. Instead, communities grappled with the complex needs of these individuals as they attempted to provide housing and services for them. The result is that hundreds of thousands of individuals were forced out onto the streets in makeshift structures that were poorly equipped to meet their needs. The mentally ill are often forced into environments that do not meet their needs and cause them stress.

A stressor is an environmental, social, or internal demand that requires readjustment and becomes a chronic stressor if present for an extended period of time (Thoits, 1995). Psychologist Richard Lazarus (1922-2002) pioneered studies of emotion and stress. He found stress often had less to do with a person's actual situation than with how the person perceived the strength of his own resources. Recent evidence strongly supports the notion that stress is "characterized by anxious apprehension, narrowed attention, and reduce autonomic reactivity... anxiety and mood disorders" (Chorpita \& Barlow, 1998).

Psychology restricts environmental stress to social forces (i.e. interpersonal interactions and personal characteristics) however Environment \& Behavior research broadens this category to include physical aspects of the environment. Environment \& Behavior research defines stress as person-environment demands that tax or exceed the individual's ability to adapt. For individuals who already have traits of Learned Helplessness (a long history of being unable to control or abate environmental stress) continued environmental stress only reinforces their feelings of Learned Helplessness and anxiety. 
It is estimated that people spend more than $90 \%$ of their lives within buildings (Evans and McCoy, 1998). Thomas David and Carol Weinstein corroborated to publish a chapter in Spaces for Children: The built environment and child development (1986) in which they explored the influence of the physical setting as "the primary medium for learning (and) understanding about social roles and norms in the world" (1986). Because the mentally ill have experienced severe disruptions, delays, and significant impairments in their social skills they continue to heavily rely on environmental cues into adulthood.

Evans \& McCoy describe five dimensions of the designed environment that potentially could affect human health by altering stress levels-Restorative, Stimulation, Coherence, Affordances, and Control (1998).

Evans \& McCoy (1998) assert "restorative qualities define potential of design elements to function therapeutically, reducing cognitive fatigue and other sources of stress... and provide resources that can attenuate stress". Restorative elements allow an individual to alter the balance between stress and personal resources by providing rest and recovery from a hectic environment. Elements that provide individuals with some degree of isolation and privacy, known as stimulus shelters, offset some stressful impacts of high levels of stimulation.

Evans \& McCoy (1998) contend that purposive actions require legible interiors and Julia Robinson adds that like clothing, the features of the architectural setting become cues for the expected behavior, as well as props to support it (2007).

Evans \& McCoy defined control as the ability to either alter the physical environment or regulate exposure of one's surrounding (1998). A design element influencing control is the response the user receiving when acting upon a setting. Unresponsive environments appear to be a major factor in the development of Learned Helplessness (Evans \& McCoy). Rivlin \& Wolfe 
(1985) also reported restrictions on personalization of objects contribute to institutionality and a sense of powerlessness among users. Closely related to the theme of control is Kimberly Dovey's (1985) and Joseph Koncelik's (1976) understanding of the importance of being able to make one's place of residence a home.

Joseph Koncelik (1976) studied the design of nursing homes and linked "home-like" features and psychological processes. Kimberly Dovey furthered our understanding of the phenomenon of home when he posited

identity implies a certain bonding or mergence of person and place such that the place takes its identity from the dweller and the dweller takes his or her identity from the place. There is an integrity, a connectedness between the dweller and the dwelling home as order and as identity are strongly interrelated; yet whereas order is concerned with where: we are at home, identity broaches the questions of "who' we are, as expressed in the home, and "how" we are at home (1985).

However, in order to make a place a home an individual must have adaptability, control, freedom, and security of tenure (Dovey, 1985). Without the features of adaptability, control, freedom, and security of tenure an individual is unable to connect with his environment in a meaningful way. The structure he lives only provides him shelter without the safety and security other individuals enjoy when they make a place a home. 


\section{CHAPTER FOUR \\ The Place}

A Residential Care Facility is a facility

which provides 24-hour accommodation, board, and care to three or more residents who need or are provided with supervision of diets, assistance in personal care, storage, distribution or administration of medications, supervision of health care under the direction of a licensed physician, and protective oversight, including care during short-term illness or recuperation (DHSS, 2013a).

There are 471 licensed RCF's in the state of Missouri. (DHSS, 2013a). Licensure allows the

facility to contract through various state agencies and receive payments for the care they provide to their residents.

The Facility

The facility in this study was built in 1929 as a small community hospital built by humanitarian efforts. Prior to the construction of the George Dimmitt Memorial Hospital medical care was either inconvenient or unavailable to many Humansville area residents; often cures were sought at home. While a few physicians practiced in Humansville before the hospital existed, they were primarily osteopathy and generally were limited to minor procedures in their offices (Mathews, 25 August 2011). Birthing, illness and accidental injuries too often resulted in death due to the lack of resources within the community. At the time Dimmitt was built, transportation facilities were limited and the nearest hospital was more than fifty road miles away. Few residents owned motor vehicles, and in fact, many families still traveled by horse and buggy. The roads were not well maintained, so this distance was often a huge obstacle to receiving prompt and adequate medical care. Also, the distance created a barrier for family and friends to be part of the treatment of Humansville area patients taken to existing hospitals in Springfield or Kansas City. 
Patients came from a wider area than Humansville or even Polk County. On March 6, 1930, for example, the Humansville News-Leader listed patients from the towns of Deepwater (Henry County), Hartville (Wright County), Osceola, Collins and Roscoe (St. Clair County).

Prior to the existence of hospitals like Dimmitt, hospital environments were neither designed nor organized with any consistent expectations about their use by patients and staff. At best, room types and hospital spaces were often vaguely designed with undifferentiated behavior settings. Patients incapable of altering their environment had to adapt their behavior to what existed even though it did not reflect behavior patterns that existed anywhere outside of the hospital. Consequently patients often found themselves forced into random, relatively undirected behavior patterns that failed to meet their needs and affected their rate of recovery.

Within its Colonial Revival façade, architects Heckenlively and Mark's design for the George Dimmitt Memorial Hospital incorporated a floor plan with specialized spaces that facilitated the work of staff in caring for the special needs of their patients while providing the latest treatment options. George Dimmitt Memorial Hospital was fitted with what was considered the latest medical technology including top of the line surgical, X-ray, sterilization and lighting equipment.

Perhaps most obviously, the changing ideology within the medical field was reflected in the design of the Dimmitt Hospital by the focus on private or double occupancy rooms as opposed to wards. Both wards and private rooms have advantages and disadvantages, but the private room design has the benefit of supporting a wide variety of ordinary human behavior by mimicking, as closely as possible, models of everyday living which are considered the optimal hospital environment (Foucault, 1973). There was a small ward at Dimmitt Hospital, but for the most part patients enjoyed the privacy of their own single or double rooms which incorporated modern 
hospital equipment yet decorated with items typically found in any bedroom within the community. The hospital was sufficiently informal that patients enjoyed the freedom to step out onto a porch from their room, sit in a rocking chair and visit with friends, relatives and neighbors.

The Dimmitt Hospital functioned as constructed until the advent of Medicare (when the Humansville community raised $\$ 25,000$ for repairs and improvements to comply with the new rules). Unable to again raise money for costly improvements mandated by the federal government, the hospital was forced to close in 1977.

The City of Humansville maintained control of Dimmitt Hospital through a management organization called the Polk County Hospital Corporation (PCHC). Later the PCHC changed the hospital's name to Polk County Hospital. By 1977, after suffering extreme financial mismanagement, the hospital was forced to declare bankruptcy (Humansville Star-Leader, 29 September 1977). The property was then sold to Osage Prairie Medical Association who slightly remodeled the interior, converting it for medical and dental offices. After suffering severe water damage in the winter of 1983 it was sold back to the City of Humansville, but remained closed. In 1986 the property was sold again to two longtime residents and was opened in 1987 as an alcohol and drug treatment center. It operated in that capacity until it was sold to its current owner, Applewood Lane Corporation, in 2001. Since then it has operated as a Residential Care Facility.

Applewood Lane Corporation purchased the property in 2001 with the intention of opening a RCF. According to the Department of Health and Senior Services, an RCFII is a: facility which provides 24-hour accommodation, board, and care to three or more residents who need or are provided with supervision of diets, assistance in personal care, storage, distribution or administration of medications, supervision of health care under the direction of a licensed physician, and protective 
oversight, including care during short-term illness or recuperation. Residents who live in a RCF are required to make a path to safety unassisted (Department of Health and Senior Services, Licensing and Regulation, 2013).

The Dimmitt hospital could not be licensed as a RCF without a Certificate of Need from the Missouri Department of Health and Senior Services, DHSS. The Certificate of Need is "administered by the Missouri Health Facilities Review Committee and designed to restrain unnecessary health care expenditures while addressing issues of community need, accessibility, financing, and high health costs." (Department of Health and Senior Services, Certificate of Need, 2013). The Certificate of Need evaluates the need for a facility to be established in the area.

\section{The Setting}

A majority of the following sections were taken from the National Register of Historic Places Registration Form which I submitted to the United States Department of the Interior in 2011 (Christensen, 2011).

The Dimmitt hospital is in the town of Humansville near the northwest corner of Polk County, Missouri. It is primarily an agricultural region in southwestern Missouri, two counties east of Kansas and two counties north of Arkansas. Humansville, with an official population of just 946, is the second largest town in Polk County. Bolivar, the county seat, has a population of 9,143. Kansas City is roughly 120 miles northwest of Humansville and Springfield lies about forty miles to the southeast. 


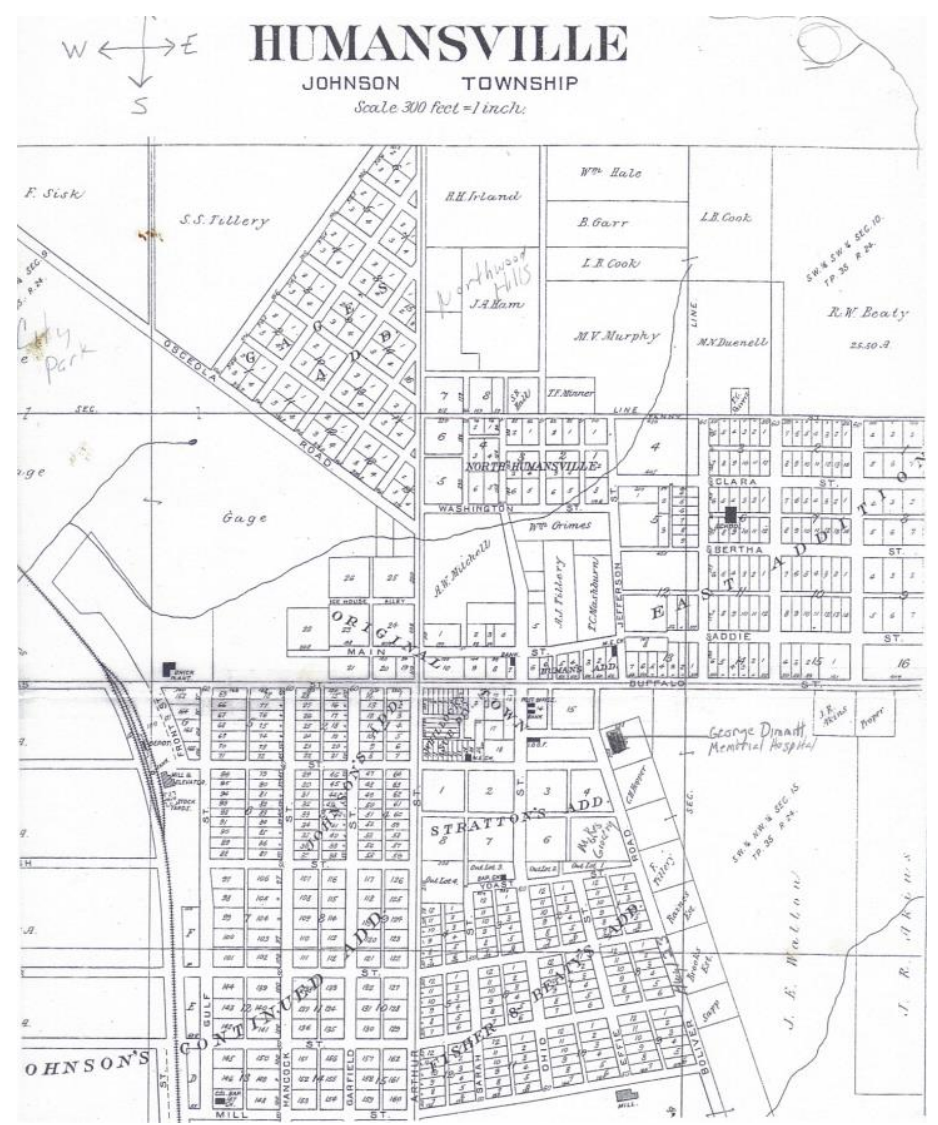

Figure 2. Humansville Plat Map

Humansville is named after founding father James Gundy Human, who settled there in about 1834 and remained until his death in 1875. A native of Knox County, Tennessee, Human built the first store in what became Humansville and was the town's first postmaster. From 1837 to 1840, he purchased forty acres for town lots (at \$1.25/acre) from the U.S. government. In 195051, Human represented Polk County in the Missouri House and was a justice of the peace for several years until his death at the age of 77. Humansville was incorporated on May 30, 1872. The railroad between Kansas City and Springfield was completed through Humansville in 1885, after which the town's population grew rapidly until, by 1902, it was between one and two thousand persons. By this time there were forty-two businesses in Humansville, along with several churches. Several doctors were practicing, usually with small offices in their homes. 
The pastor of an early Humansville church, Shady Grove Methodist (which became Humansville United Methodist) was Jonas Hare Dimmitt.

Jonas Hare Dimmitt moved to Humansville with his wife and children in the late 1880's. One of Jonas' sons, Charles E. Dimmitt, graduated from school in Humansville and married a girl from Humansville, Luella Montgomery, in 1884. Two years later their son, George Watson Dimmitt was born in Humansville. Charles became successful in Humansville in the lumber and general mercantile businesses. In 1896 Charles and his family moved to Great Falls, Montana where he became involved with the Golden Rule syndicate, which operated mercantile stores in several western states. James Cash Penney began working for Golden Rule, and in 1907 bought out Charles and the other partners in the mercantile business. Golden Rule essentially became the J.C. Penney Company which rapidly expanded. Serving as vice-president, the director and general manager for J.C. Penney, Charles Dimmitt became wealthy. In 1922, Dimmitt retired from J.C. Penney and relocated his family from New York City to Hollywood, California.

On August 20, 1928 Charles and Luella's son, George, died in a car accident in California. Subsequently, Charles and Luella returned to Humansville and donated funds for constructing and equipping a hospital for the town he cherished and the boyhood home of his son, George. As a memorial to their son, the George W. Dimmitt Memorial Hospital was constructed in 1929 with the stipulation that the hospital be "operated without profit, thus serving a great community need and extending charity to humanity" (Humansville Star-Leader, 21 November 1929). However, George did more than just bankroll the hospital. He was very much a hands-on benefactor as well, even though he was well into his 60 's at the time.

According to the Star-Leader,

during the many years of their absence Mr. and Mrs. Dimmitt retained a warm feeling in their hearts for the Old Home Town has been manifested in recent 
years by their frequent visits here, and by their splendid donations to our churches and other institutions of the town. It was while visiting here in the fall of 1928 that they purchased the beautiful brick residence property of Mrs. Harriet Beason for the purpose of converting it into a modern hospital. (21 November 1929).

In addition to purchasing the Beason property, the frontage north to Buffalo Street with the exception of a residence, pus a two-acre tract on the east and additional acreage to the west and north extending to Main Street was acquired for development. On May 21, 1929, the contract for the erection of the hospital was awarded to the Easly Brothers Construction Company of Aurora, Missouri. Work began the next day, with Creed Baccus as construction superintendent. 


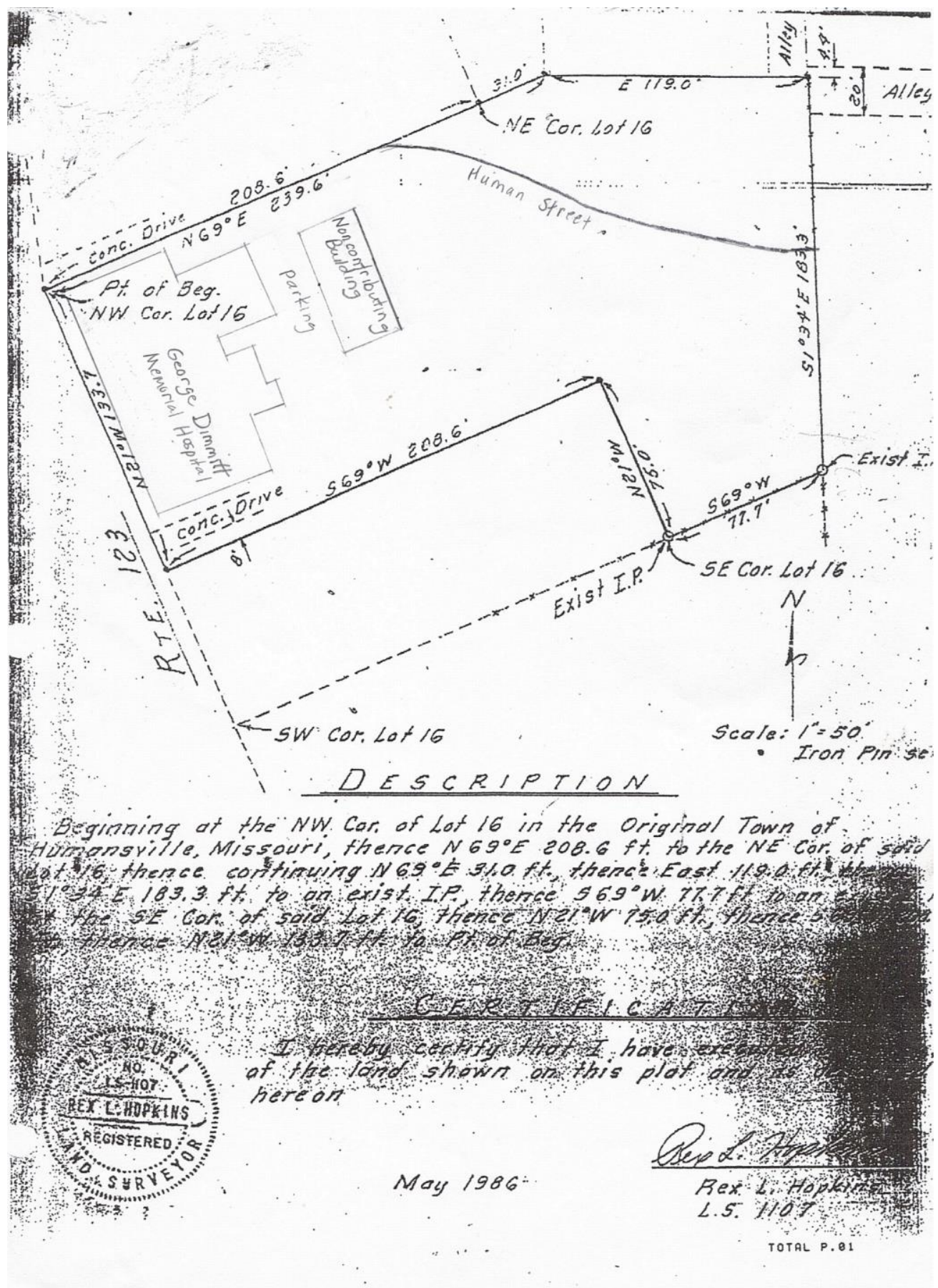

Figure 3. Lakeshores Residential Care Facility Property lines

When the construction of the George Dimmitt Memorial Hospital was completed in November

1929, the Star-Leader announced

the extent of its usefulness cannot be reckoned in dollars and cents but only in the manifold blessings to our people. Not only will this hospital stand as a memorial to their son, but it will be a lasting monument to the benevolent 
purpose and the splendid work of the donors. The people of Humansville can never hope to fully repay their debt of gratitude and only partially express their appreciation to Mr. and Mrs. Dimmitt for their great gift. (Humansville Star-Leader, 21 November 1929).

Thousands of visitors attended a dedication ceremony at the completion of construction in November 1929. After the ceremony, the building was open to visitors who reveled in its "beauty and magnificence [and] many were heard to remark that the equal of (the) building is seldom if ever found in towns of like size anywhere in the country" (Humansville Star-Leader, 28 November 1929).

\section{The Exterior}

The George Dimmitt Memorial Hospital is an irregular shaped brick building consisting of a three-story central portion flanked by two-story wings with gallery porches.

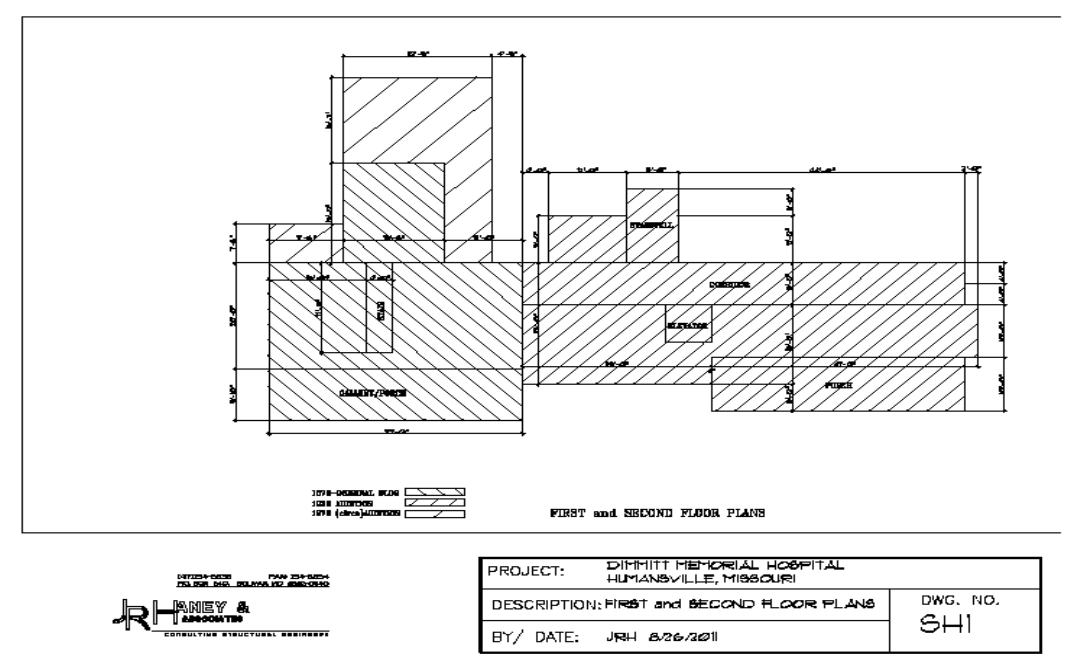

Figure 4. Lakeshores Residential Care Facility Engineering drawing

Springfield architects Heckenlively and Mark designed the attractive, west-facing hospital to incorporate an existing two-story brick residence with an ell at the north end of the property. The taller central portion contains an operating room on its top floor and features a wide frieze and cornice, centered in terra cotta. A tile band with the name, GEORGE DIMMITT 
MEMORIAL HOSPITAL, is centered in the façade. The two-story wings are side-gabled with end chimneys. The middle portion has a flat roof from which a brick elevator tower emerges. The Colonial Revival style building measures approximately 110 feet across the primary elevation and in its original form was approximately 39 feet deep at the two-story gabled ell, including the porch. In the 1970's, the ell was extended. A basement is under the entire building.

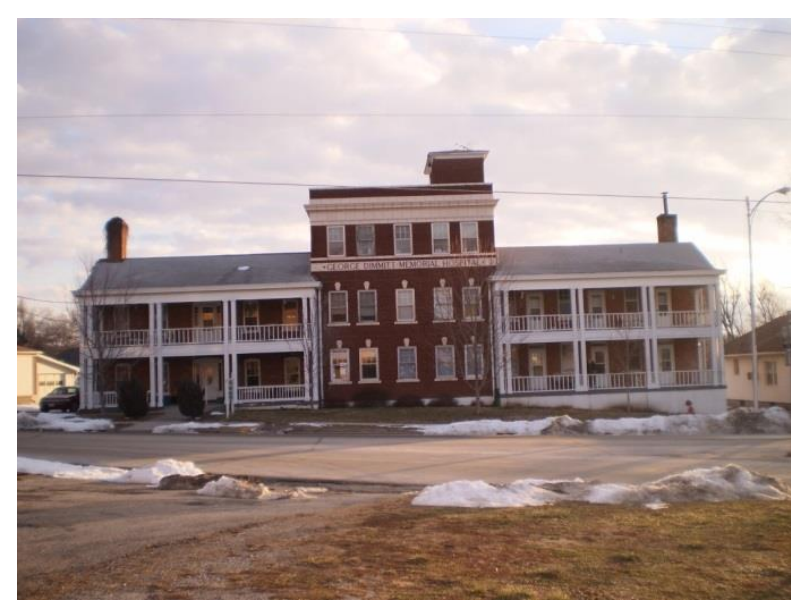

Figure 5. Lakeshores RCF West face

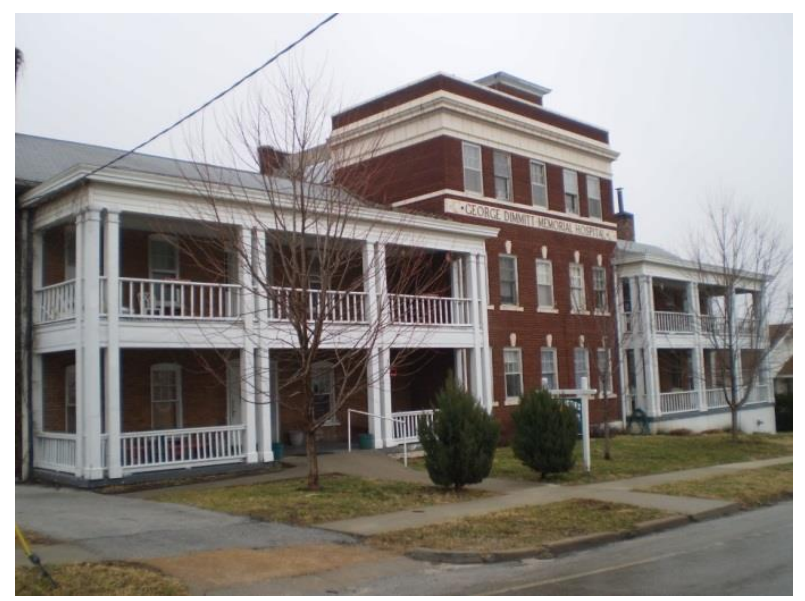

Figure 6. Lakeshores RCF from the Northwest

A concrete sidewalk runs along the front of the building parallel to Bolivar Road, and a driveway (Human Street) at the north end accesses the rear parking area. Other sidewalks access the main entrance from the north driveway and from Bolivar Road. The ground slopes southward from the approximate center of the hospital, gradually exposing more of the foundation-roughly three feet at the southwest corner. The north wing with the main entrance is on a few inches above grade, with a gently ramp used by both wheelchairs and pedestrians. Four small trees and a couple of evergreen bushes are arranged across the narrow front lawn. The hospital grounds include a storage building and a basketball half-court, both in the rear. Modern dwelling are adjacent to the hospital on both sides. The area around the Dimmitt is a mixture of residential, commercial and institutional properties near the center of Humansville. 
The brick hospital building is reinforced with steel and concrete. Bricks, laid in six-course common bond, are from three sources. Those in the three-story central portion are deep red with a hard, smooth patina and come from a brickyard in Fulton, Missouri. Bricks in the original north wing (the former two-story residence, constructed ca. 1876) have a rougher finish and were probably handmade. Bricks in the south wing resemble those in the north wing, and are said to have come from Georgia (Owens, 1982). The foundation is cut limestone clad with stucco. The stucco is scored to resemble concrete blocks.

The center portion of the west elevation with the projecting elevator shaft has a flat roof. This cube-like segment contains most of the building's Colonial Revival stylistic features. The façade is highlighted by precast terra cotta design elements such as a wide cornice, name tiles, belt courses, window sills and keystones. The low profile, shallow-molded, unadorned terra cotta cornice contributes to the overall simplicity of the style by minimizing exterior ornamentation. Three sets of five double-hung windows with six-over-one glazing are symmetrically arranged across the façade.

The wings flanking the central portion of the building are fronted with two-tier, full-façade porches under and extension of the main roof. Each of the four porches is 40 feet wide and has an ornate pressed metal ceiling. Paired square, classical columns (three in the corners) support a plan entablature faced with what appears to be wood siding. All of the trim is painted white. The terra cotta (in the central portion) is a creamy white, as is the foundation. Integral chimneys rise from each gabled end of the building. 


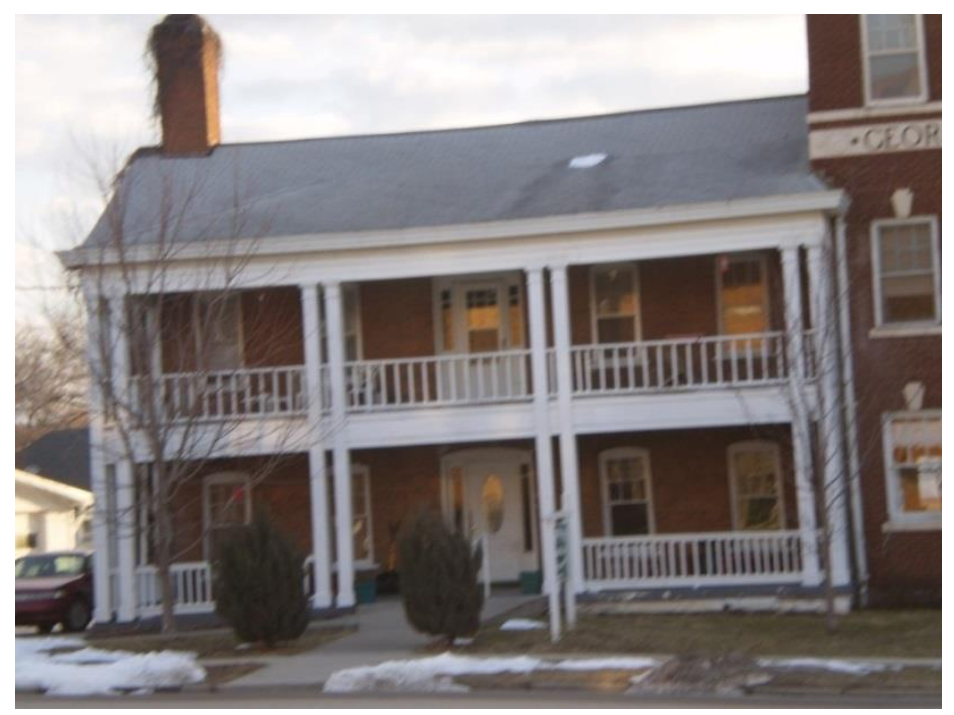

Figure 7. Lakeshores RCF North wing

Prior to becoming an integral part of the hospital in 1929, the north wing was a two-story

brick single family residence originally known as the John Garrison home. Constructed

ca.1876, it was the first house built of brick in Humansville (Humansville Star-Leader, 1902).

Probably a J-House with a central ell, the Garrison home was described as "a splendidly

constructed nine room brick house with large porches and a basement... situation on a beautiful site 120x210 feet” (Humansville Star-Leader 13 December 1928).

Central entrances on each floor of the north wing are flanked by two double-hung, six-overone windows on each side, all with segmental arches. The first floor entrance became, and remains, the main entrance to the facility. The door at this location has been replaced but the original surround which includes sidelights is intact. The upstairs entrance also has sidelights, as well as what appears to be the original or very old door. Window sills in this wing are made of wood. 


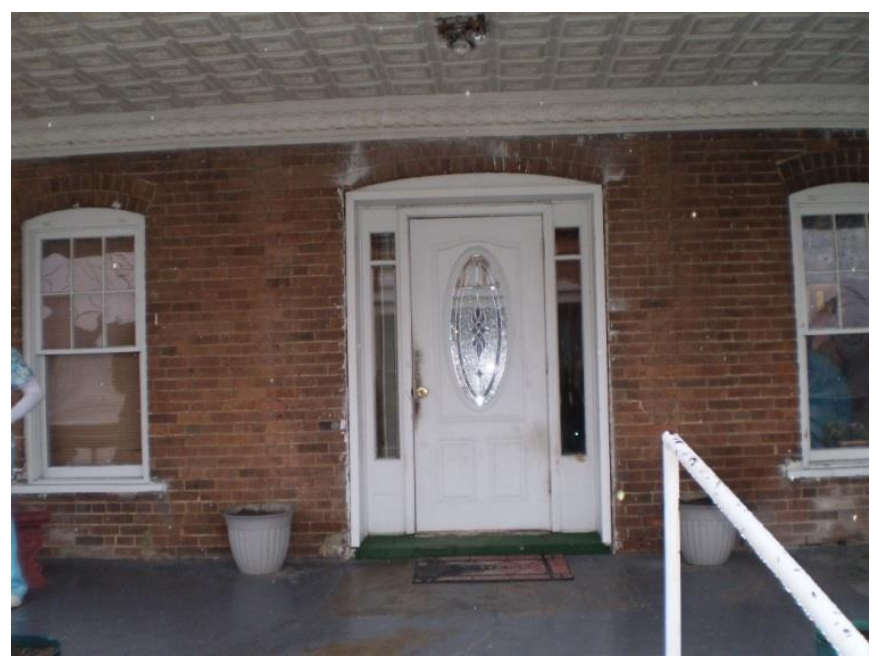

Figure 8. Lakeshores Main Entrance at North end

Although its fenestration is different and arches over openings are flat rather than segmental, the south wing is otherwise much like the north wing in size and design. Porches have the same array of columns and ornate metal ceilings but instead of a central entrance on each floor, windows and doors alternate across the façade-a total of three doors and three windows on each level, symmetrically arranged. The doors are transomed with divided glazing and windows are double-hung six-over-one units. Window sills resemble the painted wood sills in the north wing but in this case appear to be made of precast terra cotta.

The south (side) elevation is indented slightly at the rear. On each level, the main portion contains a central window with a keystone and sill similar to those in the three-story primary elevation. A small vent window is high within the gable. The indented portion also contains a window on each level, but without keystones. Except for the vented opening, all four windows are double-hung six-over-one sash. A coal door is at ground level. 


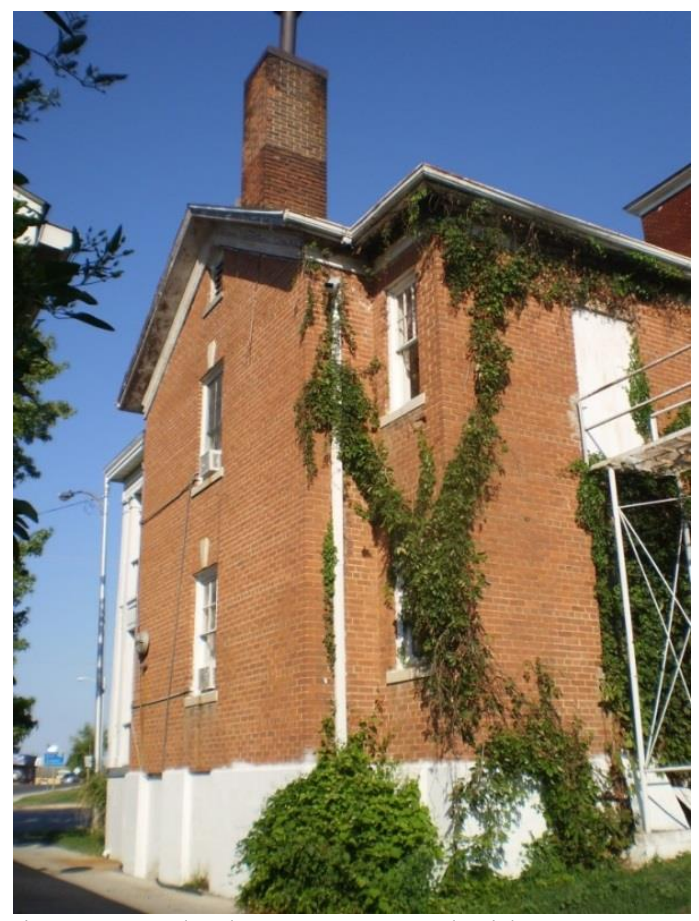

Figure 9. Lakeshores RCF South side

The north (side) elevation is largely obscure by vines in the summer months but contains four windows double-hung with six-over-one pane glazing-two on each floor.

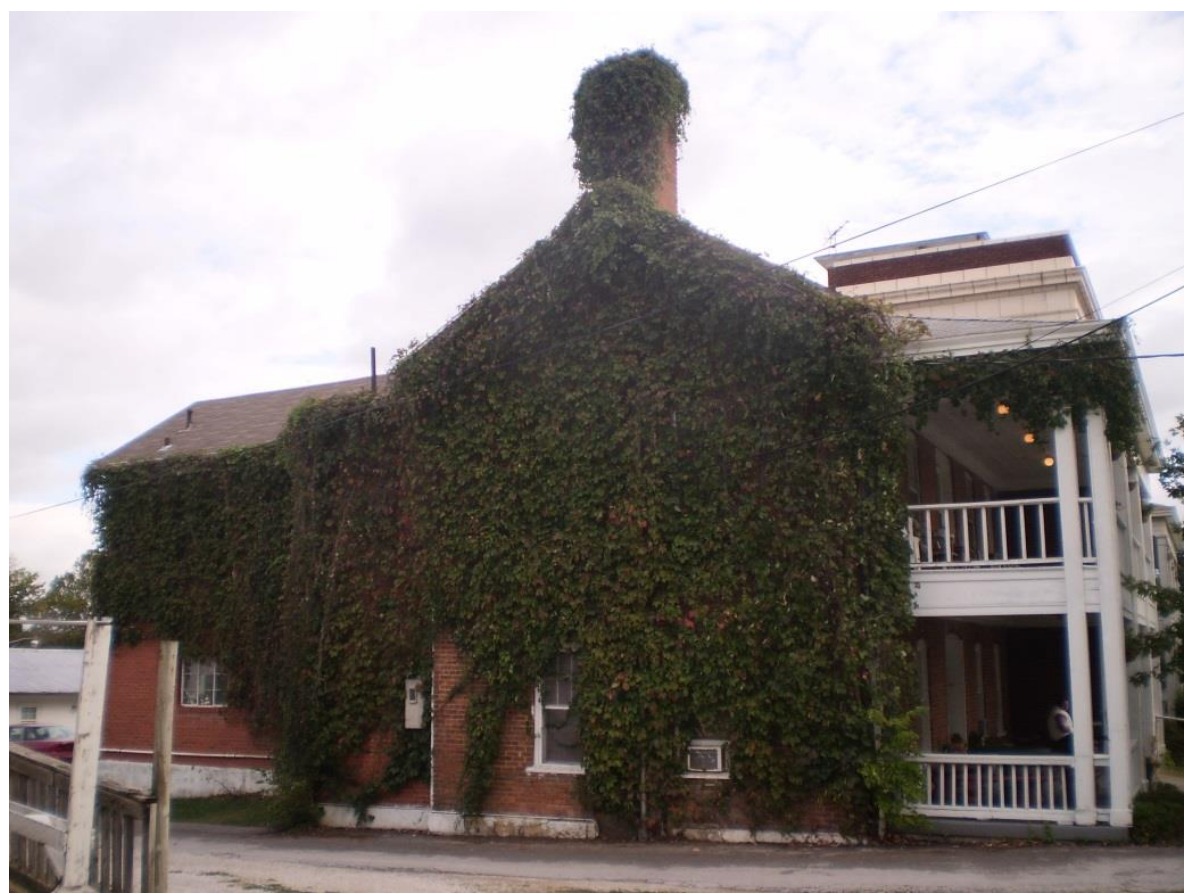

Figure 10. Lakeshores Residential Care Facility North side

The east (rear) elevation is irregular, with minimal ornamentation. Two metal staircases serve as emergency exits from the second and third floors. Windows are double-hung sash with sills 
of concrete. This elevation contains the expansion of the two-story gabled ell. Windows in the expanded portion include what appear to be casements. Ground floor entrances are located in the rear of the south wing and in the south side of the ell.

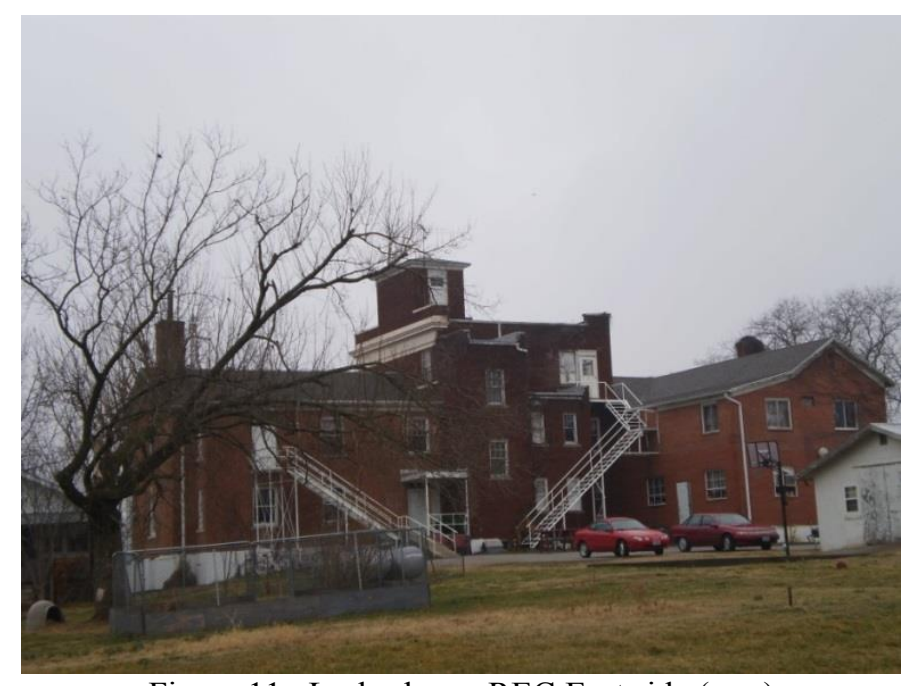

Figure 11. Laskeshores REC East side (rear)

Directly east of the facility is a one-story concrete block building with a raised-seam mental surface on its gable roof. Constructed ca. 1977, this white painted building measures 60 feet by 24 feet. A sliding vehicle door made of wood and a window are in the south gabled end. There are three entrances and two windows in the west elevation, five windows in the east elevation and one window in the north elevation.

\section{The Interior}

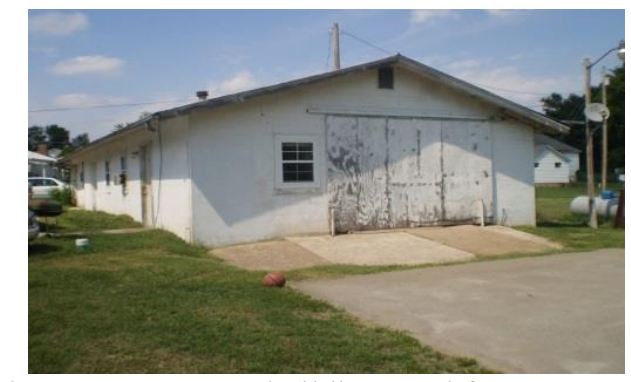

Figure 12 Concrete building used for apartments

The spaces exist today much as when the hospital was constructed. Inside the main entrance on the main floor was an admitting area and waiting room, to the right. To the left of the main 
entrance was the matron's/head nurse's room. This room is now being used as residents' bedroom.

The kitchen and dining area remain in their original locations which extended into the ell.

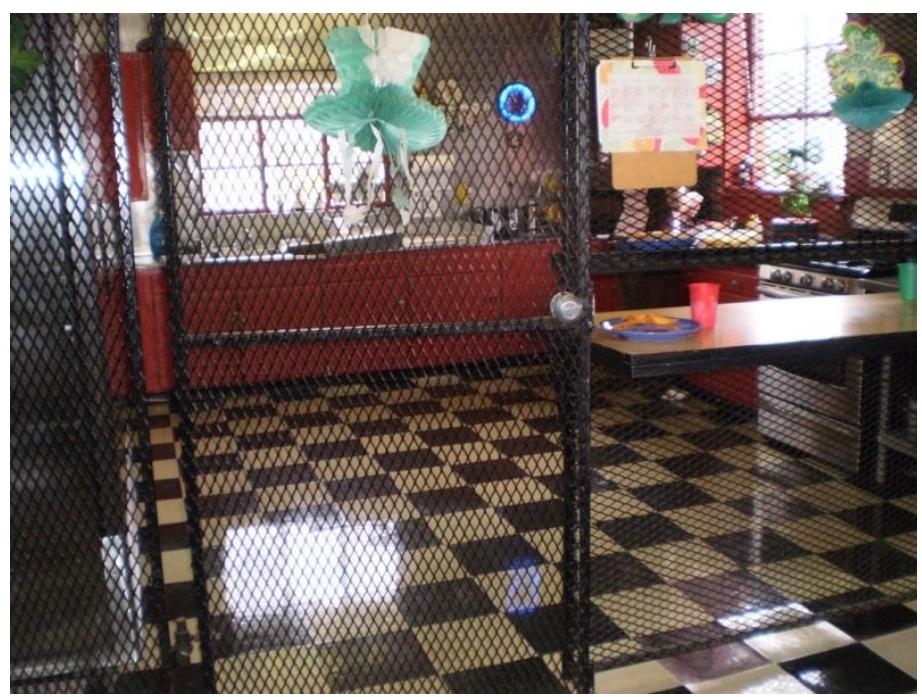

Figure 13. Lakeshores RCF kitchen

To the south were a double patient room, an office, nurses' station and three patient roomstwo double and then a private room at the far end of the corridor, on each floor.
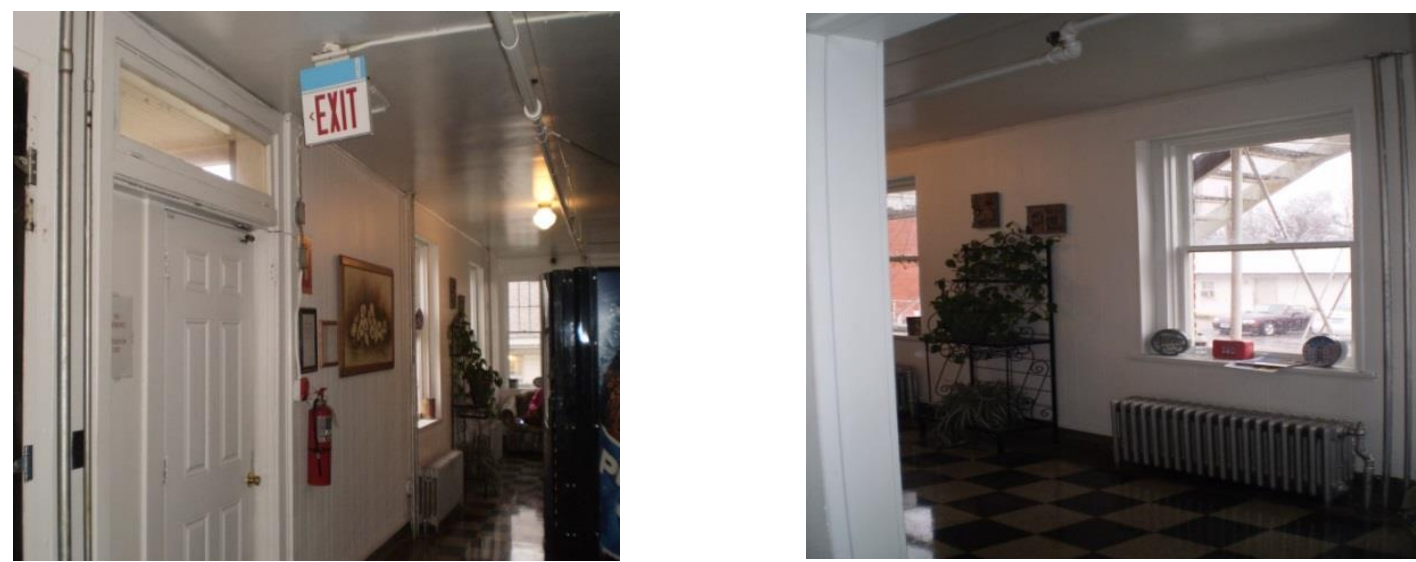

Figures 14 \& 15. Lakeshores RCF First Floor Corridor

Originally, all rooms had access to either a private or shared bathroom (none of these bathrooms have been operational for quite some time-with the exception of the use of some toilets in the private bathrooms). 


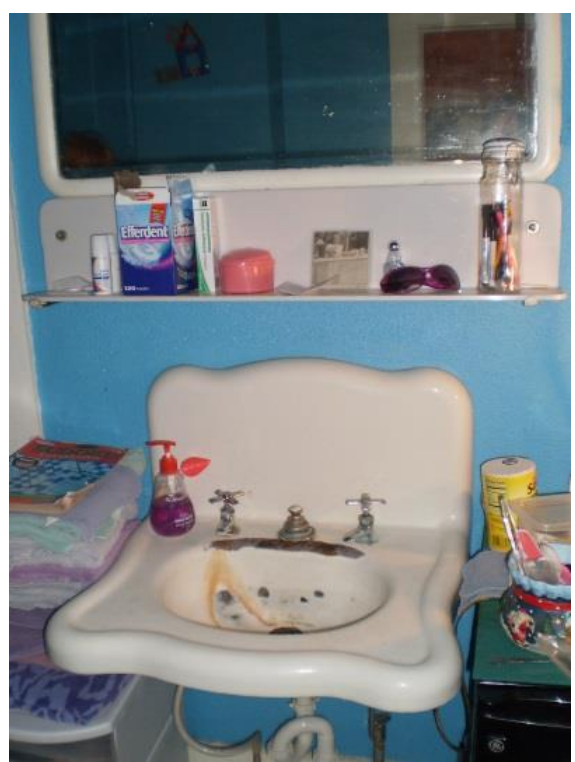

Figure 16. Lakeshores RCF Private Bathroom

Each floor also has a shower room and a restroom off the hallway, next to the stairwell.

In addition to more double and single patient rooms, the second floor also had a men's ward which was also used as a women's ward when needed, an X-ray room, a maid's room, and a nursery.

Corridors on both levels are approximately eight feet wide by seventy feet long and have mosaic-terrazzo floors embedded with brass divider strips. 

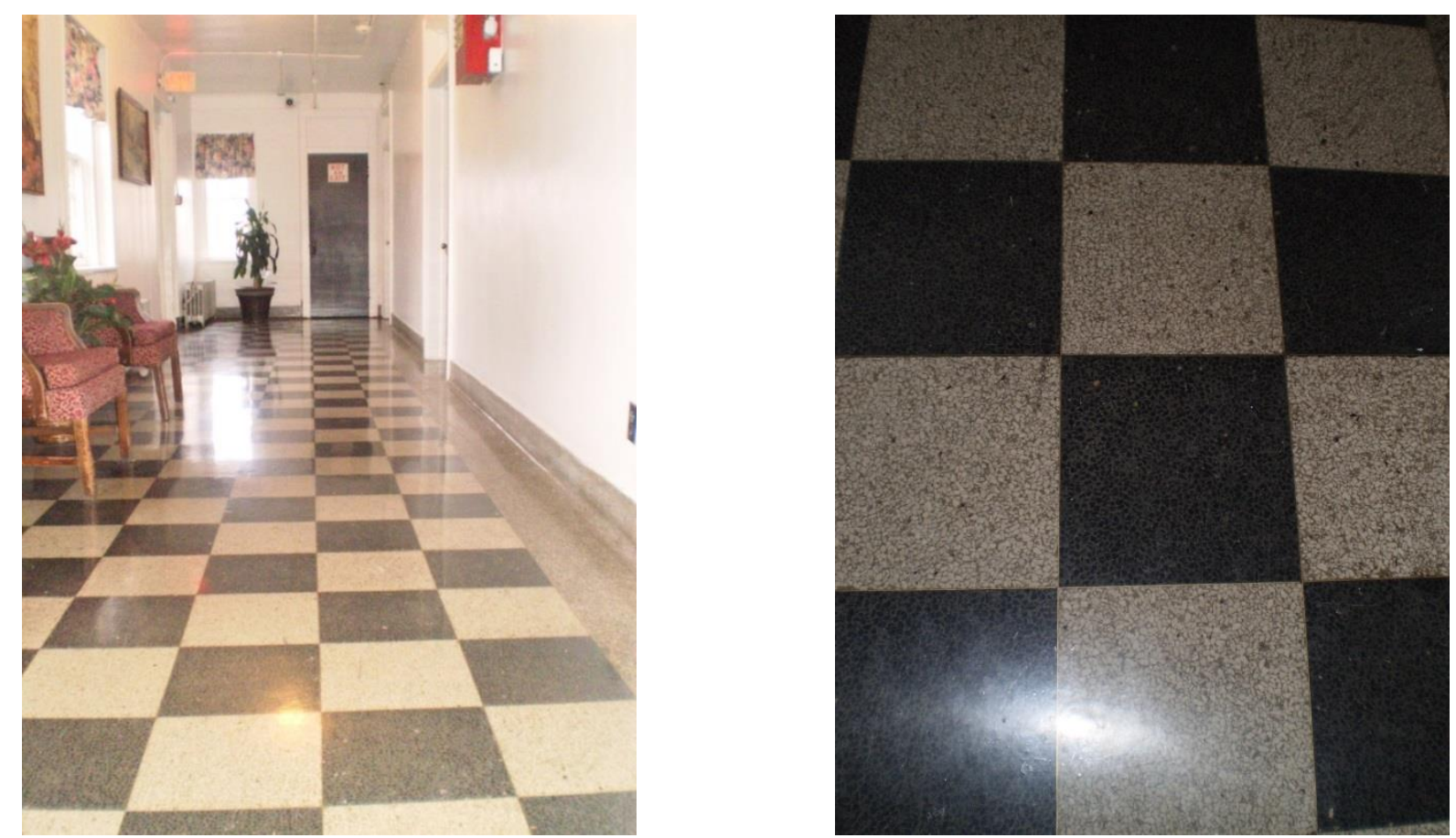

Figures 17 and 18. Lakeshores RCF First Floor Corridors with Terrazzo Floors

The hospital was designed to accommodate a maximum of twenty patients, assuming six patients in the second floor ward.

The top floor of the middle, three-story part of the hospital housed the operating room, sterilizing room, surgeon's wash-up room, storeroom, lavatory and waiting area. The operating room has walls of white tile and a floor consisting of small white hexagon-shaped tiles with a central drain.

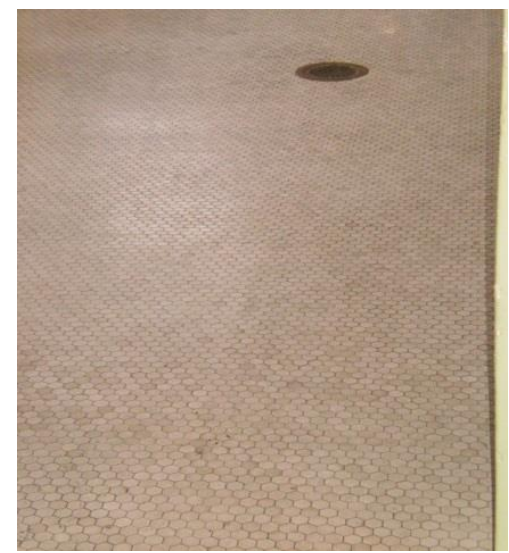

Figure 19. Lakeshores RCF Octogonal tiles in Operating Room Floor

The north wall of the operating room is plate glass and there is a skylight. 

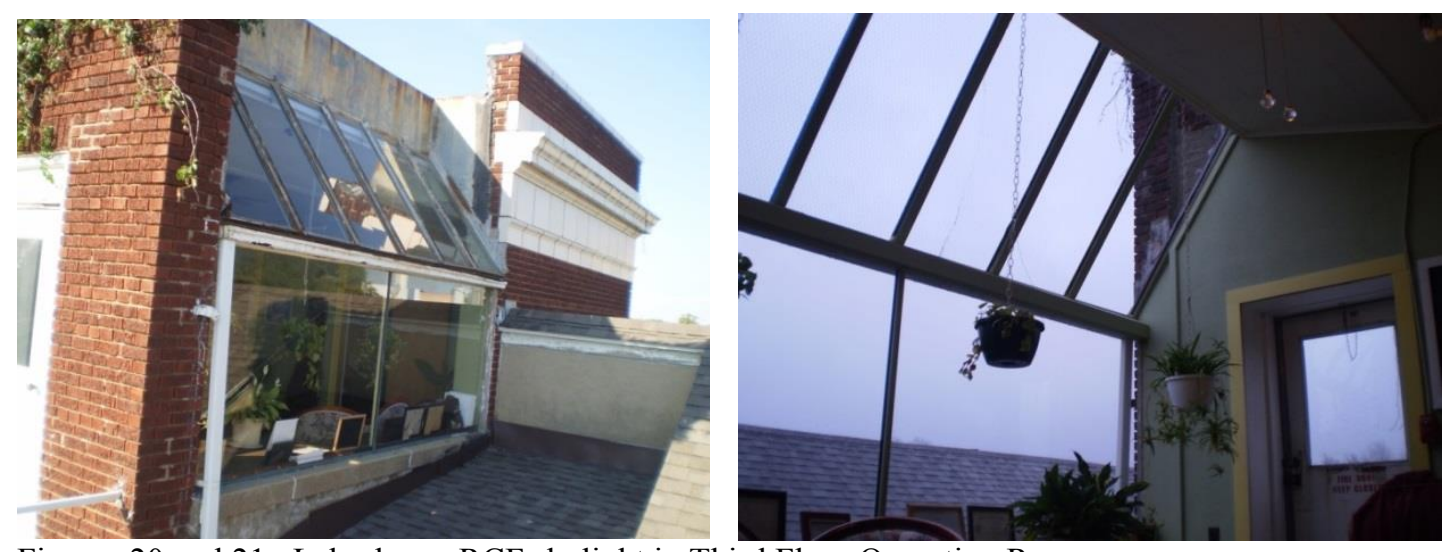

Figures 20 and 21. Lakeshores RCF skylight in Third Floor Operating Room

In addition to wide stairways, the building was equipped with an Otis Elevator system.

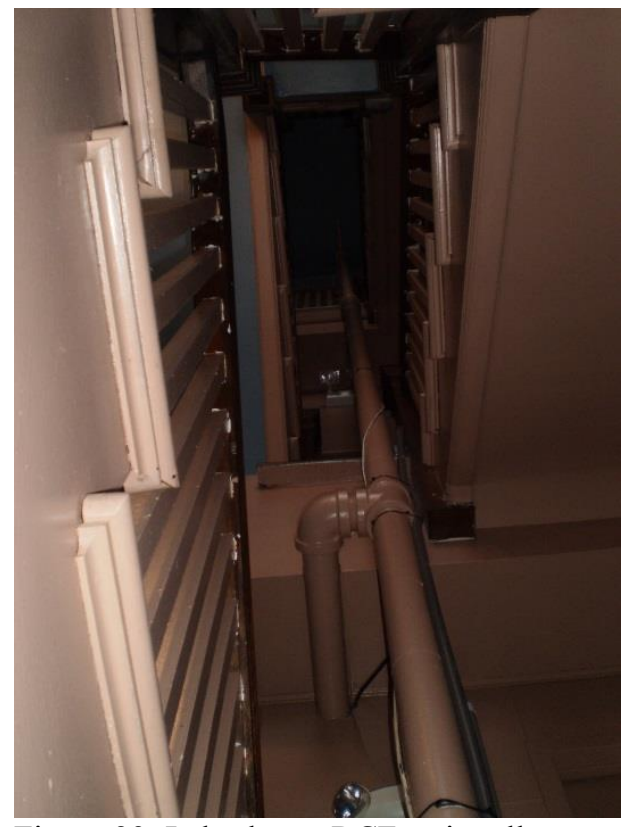

Figure 23. Lakeshores RCF stairwell Elevator

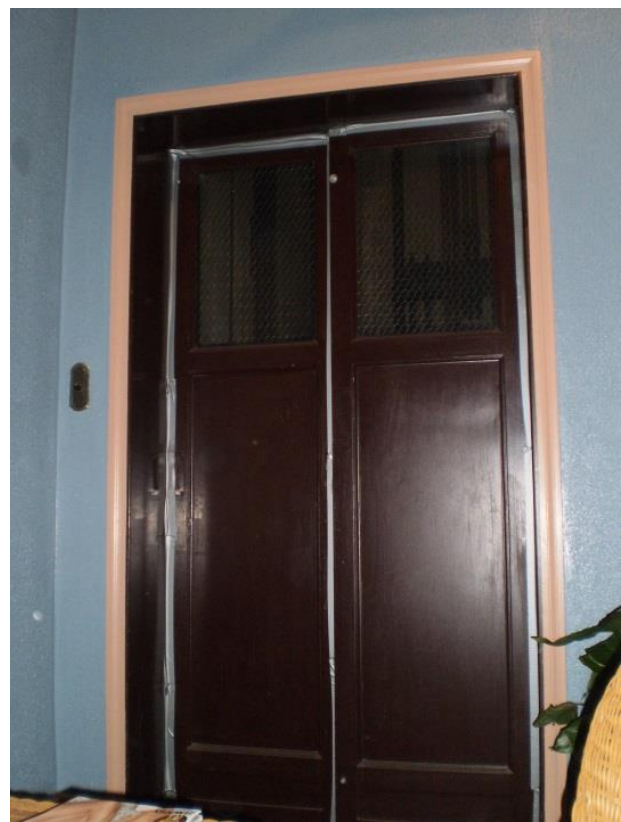

Figure 24. Lakeshores RCF Boatwick

The elevator car is built of ornamental iron, finished in grained walnut and provided with a

Boatwick type, electrically operated collapsing safety gate. The elevator remains in the hospital but is not operational. Fire and safety codes required that it be sealed so that no one could gain access.

The building's full basement contains a modern heating system, although the coal heating system is still present. The basement includes the laundry area. 


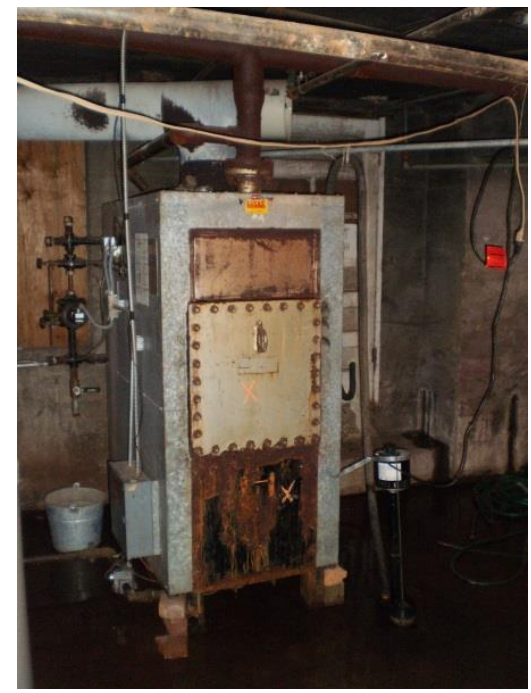

Figure 25. Lakeshores RCF Coal Furnace

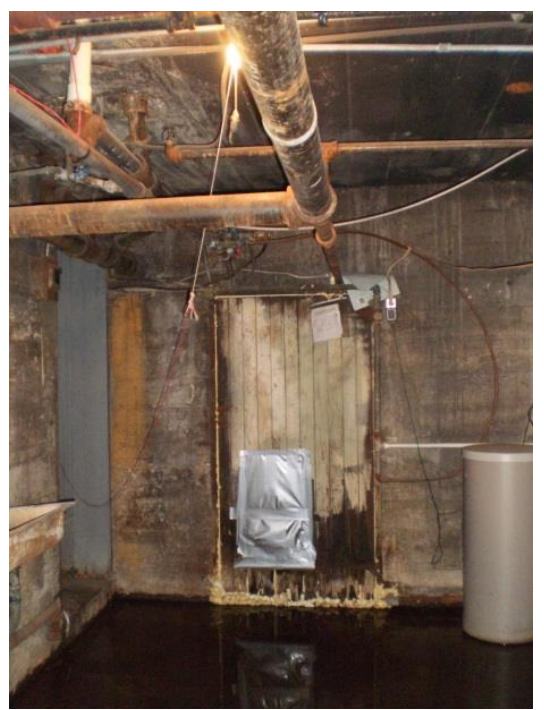

Figures 26. Lakeshores RCF Opening in Basement for Coal

When the George W. Dimmitt Hospital was purchased by the current owners in 2001, the new owners' philosophy is “to promote an individual home environment in all areas of human concern through support, understanding, and opportunity" (Applewood Lane brochure, 2010).

The organization further notes that their management and staff

are dedicated to enhancing individual self-esteem and providing opportunities for each individual in areas such as: physical and mental growth, community integration, participating and membership, daily habilitative programming and life skills, and promoting responsibility and independence. (Applewood Lane brochure, 2010).

The organization's Mission Statement also reflects ideas regarding normalization

It is our belief that in a Democratic Society, we must assist each individual in realizing his or her own worth and should lead him or her toward becoming the most worthy and productive member of society possible, operating with the least restrictions. It is our responsibility to assist an individual in choosing and maintaining a living environment that will foster and accelerate their intellectual, physical, social and career development. (Applewood Lane brochure, 2010).

The DHSS conducts initial and annual inspections of facilities. The Administrator admitted that their first inspection by DHSS, after taking over the facility, ended with 72 citations. An annual inspection of the facility was done on March 13, 2013 revealed two deficiencies: 
Protection from Hazards. (G) All doors providing separation between floors shall have a self-closing device attached. If the doors are to be held open, electromagnetic hold-open devices shall be used that are interconnected with either an individual smoke detector or a complete fire alarm system (DHSS, 2013c).

On September 18, 2012 the facility also had two deficiencies:

Ashtrays shall be made of noncombustible material and safe design and shall be provided in all areas where smoking is permitted. The building shall be substantially constructed and shall be maintained in good repair and in accordance with the construction and fire safety rules in effect at the time of initial licensing. (DHSS, 2013c)

A Plan of Correction, POS, was issued and the DHSS reported that the deficiencies were corrected by May 1, 2013 and November 14, 2012, respectively.

In 2012, DHSS came to the facility on two other occasions for a "Complaint Investigation: An inquiry into a reported problem regarding potential regulatory violations" (DHSS, 2013c). DHSS only stated the Complaint Investigation as "an inquiry into a reported problem regarding potential regulatory violations" (DHSS, 2013a).

The outcome of the Complaint Investigation was not available on the DHSS website but it appears this is well within a normal range and type of contacts among other RCF and Skilled Care Facilities in the area. 


\section{CHAPTER FIVE \\ The People}

The total number of individuals with a mental illness living in any type of living facility in the United States is difficult to obtain due to a lack of consistency among the states regarding the definition of "living facility". The National Center for Health Statistics (NCHS) first conducted the National Master Facility Inventory (NMFI) survey in 1963 and continued it in $1967,1969,1971,1973,1976,1978,1980$ and 1982 (Vital and Health Statistics of the National Center for Health Statistics, 1985). However, they had difficulty obtaining accurate data due to lack of response and definition of living facilities and have not released any additional information since 1982. A report by the CDC in 2009 estimates almost one million mentally ill residents living in nursing homes" (Centers for Disease Control and Prevention, 2008). Again, because of problems with definitions, the total number of mentally ill residing in living facilities remains unclear.

$\underline{\text { Residents }}$

The residents of the assisted living facility in this study represent a case-mix of individuals. Some have a diagnosed mental illness, developmental disability, traumatic brain injury, cerebral palsy, etc. In addition to these residents, the facility accepts the indigent as long as they have the ability to pay.

The residents are not segregated according to gender or disability. However, there are specific male and female rooms and the physically disabled are provided rooms on the first floor since the steep, narrow stairwells could be difficult to accomplish. 
Some of the residents of this RCF have a diagnosis of mental retardation. The Missouri Department of Mental Health, Division of Mental Retardation and Developmental Disabilities define mental retardation as

a condition that results in significantly sub-average general intellectual functioning that originated before age eighteen (18) and that is associated with significant impairment in adaptive behavior...that is likely to continue indefinitely (DMH Legal and Advocacy).

Individuals are most likely identified in elementary education programs. Children entering the public school system go through a variety of testing throughout their educational years.

The Missouri Department of Elementary and Secondary Education (DESE) Students identifies those students with disabilities as

those students who generally have significant cognitive deficits as evidenced by one of the two methods: The student obtains scores falling four or more standard deviations below the mean on standardized measures of cognitive functioning and shows commensurate deficits in at least two areas of adaptive functioning, OR; the student is not able to respond to any standardized measure of cognitive ability due to a combination of sensory and/or motor impairments, but diagnostic information indicates significant deficits in intellectual and adaptive behavior skills, and the student requires pervasive level of supports across all life areas, as defined by the American Association for Mental Retardation (AAMR) classification system. (DESE, Educational Services Provided to Students with Severe Disabilities).

If a child is identified as demonstrating deficits "a multi-disciplinary team consisting of the student's parents, educational specialists, and medical specialists in the areas in which the individual demonstrates problems work together to plan and coordinate necessary services" (DESE, Educational Services Provided to Students with Severe Disabilities, 2013). These children will be advanced through the public school system through the development of an Individualized Educational Program (IEP). The IEP (Exhibit 1) outlines short-term objectives the child is expected to achieve. Beginning around the age of sixteen (16) the team, including the student, will develop a Transition Plan (Exhibit 2). 
The Transition Plan allows the team to determine whether the student will exit the public education through earning the required credits or meeting IEP goals and objectives. The Transition Plan identifies other post-school adult living objectives such as "acquisition of daily living skills... a functional vocational assessment." (DESE, Transition Plan). Some students may advance to a higher education or may be trained in vocational programs. However, DESE notes

the presence of significant cognitive deficits may permeate a student's educational condition so as to render him/her severely disabled. A student with severe or multiple disabilities would evidence the presence of significant cognitive deficits along with one or more of the other educationally disabling conditions. (DESE, Educational Services Provided to Students with Severe Disabilities, 2013).

Due to the profundity of their disability, some students will experience disabilities that prevent them from living independently as adults. The Missouri Department of Elementary and Secondary Education (DESE) states

according to the National Dissemination Center for Children with Disabilities (NDCCD), people with severe disabilities are those who traditionally have been labeled as having severe to profound mental retardation. These people require ongoing, extensive support in more than one major life activity in order to participate in integrated community settings and enjoy the quality of life available to people with fewer or no disabilities. They frequently have additional disabilities, including movement difficulties, sensory losses, and behavior problems. People with severe or multiple disabilities may exhibit a wide range of characteristics, depending on the combination and severity of disabilities, and the person's age. There are, however, some traits they may share, including: limited speech or communication; difficulty in basic physical mobility; tendency to forget skills through disuse; trouble generalizing skills from one situation to another; and/or a need for support in major life activities (e.g., domestic, leisure, community use, vocational). (DESE, Educational Services Provided to Students with Severe Disabilities).

DESE adds that medical problems that may accompany severe disabilities include seizures, sensory loss, hydrocephalus, and scoliosis. The IEP identifies what post-graduation services will be required and what agencies will provide services. Usually by this time, these individuals have been involved with a variety of public and private agencies. These agencies provide 
financial and support services to their families. Missouri Department of Social Services provides families with Income Maintenance \& Self-Sufficiency Programs (Food Stamps, Health Care and Child Care Subsidies), Missouri Department of Mental Health administers programs

that can help children and youth with developmental disabilities get some of the services they need. Some programs provide direct services. Other programs help pay for services. Programs may have financial or other eligibility requirements. The services your child receives may depend on individual and family circumstances. (DMH, Financial Resources for Missouri Children and Youth with Developmental Disabilities).

In addition, financial assistance is provided by the federal Social Security Administration for children from birth up to age 18 with Supplemental Security Income (SSI) benefits. This program provides a monthly cash payment to the parents of disabled children to use at their discretion. If children under the age of 18 qualify for SSI benefits due to a disability they will most likely qualify for benefits as an adult.

Two of the three public administrators discussed the current trends in diagnosing children in the public school system. One public administrator stated "we're going to have this whole generation, two or three generations... and they're (government agencies) not wanting to identify them in the school system" (Bond, 2013). She tells of one of her wards

She's 23 now, but I got her when she was 20. Nowhere in any of her things does it say, in her IEP's or anything, that she's developmentally disabled or MR....(S)he did get an evaluation.... and she tested at a sixteen which means that she's below the level and that she is mild MR....but I can't get somebody DMH services if I don't have a document before the age of 18 that gives them that diagnoses. So if we push them through the school system without giving them any labels...the state doesn't have to step in" ( Bond, 2013).

All of the guardians agreed that the government is "doing less and less all the time. And they're going to do less and less all the time" (Bond, 2013). Another public administrator discussed how the public school system is now labeling children as "borderline intellectual functioning" instead of "mentally retarded" (Davolt, 2013). She stated "they changed that a few 
years ago... so that they couldn't get services 'cause it's not a qualifying diagnosis (for DMH funding)" (Davolt, 2013).

The residents interviewed expressed a long history of psychological issues and personal trauma. Access to information regarding their family history was not accessed for this study, however, through their stories we can get a glimpse of family mental health issues.

R.C. grew up in Maine with a twin sister and two brothers. She recalls a tormented childhood of abuse and neglect. She moved to Texas when she was 18 years old, two years after her sister moved out of the home. She has not had any contact with any family members since she left in 1987 and when asked if she wanted to reestablish contact she replied "It's too late. I left when I was 18 and I've had no contact with them all this time".

When asked about whether she wonders if her family of origin is looking for her, she says, "they're not my family now since I'm adopted." R.C. was adopted at the age of thirty-two by a couple who "wanted a child together so (she) paid for the adoption and it went through." She had met the couple during her employment at New Beginnings and had known them for five years at the time. She moved into their home and they lived as a family unit until, she states: "my therapist was drugging me up pretty good and my father was drunk one night and decided to rape me...My adopted mom didn't believe me. She kicked me out." When asked if she continues to have contact with her adoptive parents she says "they don't have anything to do with me." Her inability to cope with this situation caused her to have "a nervous breakdown after (she) had (her) gallbladder removed and the doctor messed up and caused a bowel leak and (she) nearly died." Then, she states, she got "tired and the abuse and getting stomped on ...finally got the nerve to o.d....and that's what brought me into a group home." R.C.'s guardian reported the following 
She was adopted...(T)he adopted mother tells me that the adopted father (and R.C.) had an inappropriate relationship. As far as (R.C.) says, it comes from the father, and of course the adopted mother says it came from R.C.... it takes two to tango. So I just believe it was everybody's fault, you know. She was married...She's been all over the United States. She actually worked at one time as a clerk for New Beginnings. (The in-patient acute psychiatric unit at the local hospital). And now she becomes a patient over there (Bond, 2013).

She lived in one group home after another for the next couple of years, staying for only a few months at each, prior to coming to this facility about four years ago.

R.C. seemed complacent to the dismal redundancy of her day. She relinquishes control of her daily life to the rules and routines of the RCF. She reports her average day consists of getting up at 5:00 and doing my blood sugar and insulin. I get up and go into the office and do my own blood sugar and then I go back to bed until around 8 . Then we get up at 8 and we take our 8 o'clock morning meds. Then I go in and make my bed and straighten up my room. And then I wander around the hallways and talk to my friends and try to find things to do until 11 o'clock meds and then lunchtime is about 11 o'clock. Then we take our meds at 12 and then usually, I take a rest until 2. And then I get a 2 o'clock med and then I usually rest from 2 to 4 . Then I take a 4 o'clock med and 5 o'clock blood sugar and 5 o'clock meds and five-thirty dinner. Then I usually take down time. My down times comes as reading or relaxing or listening to music. It's the same thing day after day.

In her room she has a tv, computer, and a Kindle Fire hd that her guardian has purchased for her over the years. R.C. shares a room with two female roommates.

R.C. expressed a futility in responding to her situation when she discusses her issues with her living arrangements. One roommate "has seizures and she forgets a lot of things. And when she gets into one of her moods she gets difficult to live with." She has problems with the other roommate because "her space is a dive". She describes the rules of the RCF as "being too strict" and says "like one rule is there's no going back to bed after 8 o'clock meds in the morning. She found his rule difficult to follow because “sometimes you're tired because your 8 o'clock meds make you tired". 
She has also experienced a difficult time with rules regarding relationships within the RCF. When asked what are some of the rules that are broken at the RCF she replied "no sex." She has had three intimate relationships since moving to this facility even though "you can't have boyfriends and girlfriends here." She recalled a time when she

was dating someone here and they broke us up. He lived upstairs and I lived downstairs and staff came into my room and told me I was banned from going upstairs and that I was banned from being around him and I couldn't talk to him and couldn't be near him.

She says "in a place like this you get close to people and you get feelings for people and it's so hard...not to feel for somebody...we live in such a tight, tight community here that it's hard not to develop feelings for each other." In spite of disagreement with some of the rules, she considers her interactions with to be positive. She says "the staff "does our meds...they cook our meals...they do our laundry...they clean our rooms....they talk to us when we need talking to.....and they remind me to do my daily ADL's."

She described ADL's as “daily living skills...I don't know what the A stands for. You know, take a shower." She says "sometimes I get lazy and stuff and don't take a shower and they give me reminders and stuff." When asked about how staff would know if she took a shower she says "there's a camera to see if we go take a shower." She described this facility as "a homey place. We're more of a family here. It's more family based." She calls the administrator of the facility "momma" and says "it's like we're her kids and she adopted us." When asked what type of things makes this facility a homey place she recalls efforts by the staff and administration to give us special dinners during the holidays. Momma makes out our birthday list for our birthdays and she asks us to write down one thing we want for Christmas and she goes out and plays Santa and we each get one thing for Christmas on Christmas Day. They stuff our stockings and we have a stocking party and they decorate for Halloween and Thanksgiving.

Her community interaction involves "going to the library and that's about it." 
Her goal it to move into her own apartment in a local community however, she says, her symptoms from schizophrenia, anxiety and pica have prevented her from achieving this goal. She says her medications are helpful but she feels her pica is like an addiction that she struggles with on a daily basis and her "voices...never go away."

Another resident, a 34 year-old female, has lived at this facility for almost two years. H.F. appeared very eager to participate in this study. When introduced she quickly accepted the earliest time available. Even still, H.F. was very guarded in her answers and only divulged favorable information that presented her as a competent individual. She discussed how she was self-sufficient because she "was able to cook for myself... able to go do my own laundry...bought my own food with my own money".

She reported that she was born and raised in Oregon. She was held back in school for two years "because of a hearing disability". She revealed an early history of psychological issues while talking with a male resident in the rec room at the RCF when she yelled "What choice do I have in it? What choice does a 7 year-old girl have about taking medication?"

H.F. also expressed a lack of agency when it came to dealing with life crises. When asked how she ended up in this area she stated "I married an asshole". She recalled living in Oregon when her "son passed away...ended up choking on his vomit. He was seven weeks when he passed". She explained that after feeding the infant she fell asleep with the infant in the bed with her. While she was asleep her daughter, who was 4 years old at the time, rolled the infant over and he asphyxiated on his vomit. She recalled her mother-in-law, who lived in Missouri, flew the infant to this area for burial and after that she, her husband, and two young daughters moved here also. She had another daughter after moving here. She reported seeing her three daughters within the past month but stated she "rarely gets to see them most of the time". 
She described the situation that led to her guardianship as "a money situation." She was living on her own until she was 30 years old then "had some problems...living at friends' house and then they broke into a convenience store. And I had no money to get my scripts". She recalled getting a guardian because she "couldn't manage (her) money. If you have no money you can't manage money". She was approved for Social Security Disability a few months after she was appointed a guardian.

H.F. stated she lived in a nursing home for about 16 months. She stated she liked living at the nursing home because "they fed us better" and she had her own room with her own bathroom and shower. Her guardian stated that she was pressured by H.F.'s caseworker to try a transitional apartment program through DMH.

Her guardian, Bates County Public Administrator, Sharon Cumpton provided the following information

she knows everything. She thinks she has a medical degree. She doesn't. She has three children. They live with her ex-husband even though one of them is not his, but he still has custody. Actually, I'm not sure if they're divorced, I don't know. She has a lot of health issues, she thinks. She's had knee surgery... There's been a lot of issues through the years. She's not appropriate with them...One instance was they lived, the husband travels a lot, he left them with friends or people, whatever....and they went to pick her (H.F.) up and took her home to visit for the weekend. And they called and said (H.C.) can't come over any more, she can't stay overnight...They said...she (H.F) had her cellphone and her middle daughter, who was 10 or 12, was playing with it and there was a picture of (H.F.) masturbating on it. (H.F.) likes men. She's very high functioning to talk to. I think she has a pretty high I.Q. She can tell you about her meds, her illness, all that kind of stuff. She wants to live out on her own. She thinks she's going to move into an apartment soon. She was selling her meds when I got her. She was homeless. She had been living with some guy here in town. She tries to manipulate the doctor to get what she wants. She likes her meds. She grew up in Oregon. She was living in Adrian. She got thrown out of HUD housing before I got her (Cumpton, 2013)

Sharon Cumpton recalled the time she placed H.F. in a " transitional apartment where they have oversight for meds but the residents were supposed to keep their room clean....and there 
was two kitchens, dining room and living room and they had to take care of it" (2013). The transitional apartments are in "an institutional looking building" on the side of the Department of Mental Health office in Nevada, Missouri (Cumpton, 2013). The residents were also required to attend meetings and work with their case managers on budgeting and daily living activities (DLA's). Sharon Cumpton stated this arrangement “didn't even last three months and she got kicked out. She took part of her money and went out and bought booze and some of them were young" (2013). H.F. contributes the failure of the transitional apartment program to her roommate's underage drinking. After the failure at the transitional apartment in 2012 her guardian moved her to this RCF.

At this RCF she has been in charge of the resident coffee fund. She states

I know how to totally budget. I am the only one in charge of certain aspects like coffee money and stuff like that...I'm the only one that's held responsible to hold the key. I'm in charge of the coffee money but I know that I can do that and manage it because I'm the one that volunteered to do it but it's like nobody can manage it.

Her goal is to "get my life back. I want my girls back. I want a life. I don't want to be here". She says that her "anxiety" is standing in the way of achieving her goal despite taking the "the highest dose of Buspar that I can be on."

D.A. is a 53 year-old under guardianship with the Polk County Public Administrator, Barbara Davolt. Throughout the conversation D.A. experienced excessive delays in response time, difficulty providing accurate information regarding dates and times and went into a catatonic state for almost two minutes. Barbara described D.A. as:

His hair is buzzed, it's black. He's got a beard...kinda bigger, taller guy...doesn't like to shower...talks to himself a lot. The goal of moving out is always his goal. But we're never gonna get there unless a miracle happens. Just 'cause he's not gonna get up. He can't get up and shower and shave...He's got tons of potential... all the potential in the world. If we can just get him to do, you know, the things we need him to do... on a regular basis and not have to wake him up 50 times in the morning. You know you just have to babysit him so much (Davolt, 2013). 
Later, Barbara added "D.A. sent me the sweetest card this past summer, spring. Out-of-theblue. He's never sent me anything" (Davolt, 2013). D.A. appeared very subdued throughout the observation and introduction and appeared to be MR or overmedicated. When formally introduced he seemed bewildered so numerous explanations were given using the simplest language possible. D.A. was not observed participating in the flurry of activity throughout the corridors.

As an adult he moved into an apartment in the town he grew up in. He received services from several agencies. Since he was already diagnosed as mentally retarded he received case management from Joplin Regional Center and Premier Health provided in-home services. Premier was "supposed to come in and help cooking, cleaning and shopping but all they did was sit on their butt". He got evicted from his apartment because he "got picked on there a lot, everybody was calling the cops on me all the time".

Finding himself on the brink of homelessness, his case manager from the Regional Center helped him find an RCF about 50 miles from his home community. He lived there for about 6 months until he got kicked out. He then went to live at a nursing home in Humansville because "he had no choice in the matter...I had very few days to find a place to live so it was either that or live on the streets". After living at the nursing home for several months he came to live at this facility in 1996 but only stayed for "a little while" before moving to an RCF in Springfield. This RCF in Springfield lasted "one week and one day until (he) almost died from an allergic reaction to medication". When he got out of the hospital he went to live in an RCF Bolivar. He stayed there briefly until his "dad got really sick" and he "was getting ready to lose (his) guardianship anyway". After guardianship was approved in 2002, his guardian placed him at this facility. 
Both of his parents are deceased and the only other family member is a brother, his wife and their children in the state of Washington and he has little contact with them. He attends a community church but did not have any other ties to the community. The only "visitors" he receives at the facility are his guardian, case manager, and other professional staff.

When asked what he most liked about living at this facility he said "the friendly staff" even though "I get mad at them...they get on to me about sleeping too much".

His goal is to live in his own apartment in Springfield because he does not like the local hospital. He understands that his independence requires him to "get my act together...start obeying the rules... start being med compliant...start doing my hygiene". When asked about hygiene he admitted to "faking showers" by saying

I like to go into the shower and turn on the water and then I'll set on the toilet and not take a shower and make everybody think I did. Then I'll wet my hair down and then I'll put soap on the rag and make them think I really did take a shower when I didn't.

He didn't know why he doesn't want to take a shower but understands this behavior as preventing him from living in his own apartment. In spite of this he believes he would be successful living in his own apartment with some services.

Despite D.A.'s report that he "fired them....cause they weren't doin their job and I didn't like them" he continues to receive services through Springfield Regional Center (SRC) due to his mental retardation diagnosis. SRC provides him with a case manager that can assist him with every aspect of his life. A case manager works with high guardian and can help him secure housing and maintain eligibility for federal and state assistance programs. In his own apartment the case manager would also work with the guardian and private agencies to setup up services such as psychiatric care and other medical care, transportation, medication administration and inhome care. 
While at this facility, he continues to receive Community Integration (CI) services through SRC. An individual meets with him a couple times a month to "go out to eat, go fishing...a bunch of this and that". He also attends the Psychosocial Rehabilitation (PSR) activities though the local CMHC.

\section{$\underline{\text { Guardians }}$}

Twenty-eight of the thirty residents at this facility have guardians. A majority of the guardians are Public Administrators. A Public Administrator is an elected position. Their election years coincide with presidential elections. Greene County, Missouri defines the Public Administrator's mission as

Its shall be the primary responsibility of the public administrator and her employees to work toward improving the quality of life of persons under guardianship while protecting the ward's dignity and self-respect. The ward's right of self-determination shall be observed whenever possible. The growth of the ward shall be encouraged through his/her increased participation in decision-making. The public administrator and her employees shall use the standard of informed consent when making decisions on behalf of the ward. All employees shall understand and follow the National Guardianship Association's Code of Ethics. Further, all must understand that the guardian/conservator is required to exercise the highest degree of trust and loyalty when making decisions for the ward/protectee. (Greene County Public Administrators, 2013).

This does not mean that the resident was from the county where the Public Administrator was appointment as their guardian. Several situations were presented by the Public Administrators regarding situations that required their involvement with individuals who were not from their county. One public administrator recalled

two different homeless situations we've had just this year. One gentleman was frequent in the ER. Basically, he'd get drunk and go out there and say, 'I'm contemplating suicide.' which gets him a bed, meal....all his needs. But he did that in 2012 thirty-six times. (H)e'd been in an out of jail several times-public intoxication, indecent exposure, because he was homeless and after a few drinks he urinated behind a building and someone saw him (Davolt, 2013). 
In this case the psychiatrist at the hospital filed a petition with the court to have the county Public Administrator appointed as his guardian. The public administrator recalled that this case was "tricky" because when the man appeared in court he was "very coherent, very educated, very dirty, but you know, that's his choice." (Davolt, 2013). The homeless man took the witness stand and stated "'last time I checked I didn't know being homeless was against the law"” (Davolt, 2013). The Public Administrator, while agreeing with that statement, reported that, in the end, she was appointed his guardian because "he was using the hospital as a motel, using the jail as a motel...threatening to starve himself in the county jail...saying 'I'm going to starve myself in your county jail and this is going to be bad publicity for all of you.' And he did stop eating" (Davolt, 2013).

Another male was appointed a guardian as a condition of probation through the Department of Corrections. Both are in locked facilities because they are considered elopement risks. Sometimes a person will be appointed a guardian through the Department of Health and Senior Services. If a representative from that agency determines that an individual who is elderly or disabled in any way requires a guardian a petition can be filed to have one appointed. Another public administrator recalled several incidents with the elderly where "their families spent all their money...They dump them in a nursing home and then...they can't stand to see them so they don't come back and they don't answer phones. Nursing homes call me and say we can't get ahold of any family" (Cumpton, 2013). All of the Public Administrators also relayed stories about how "family dynamics are good and sometimes they work, but a lot of times they don't" (Cumpton, 2013). Another Public Administrator stated “you’ve either got family that can’t because they've financially exploited the individual...And then you've got others...the aging who've had their disabled child at home all these years and they are passing or too old to take 
care of that person anymore" (Davolt, 2013). Greene County described the role of Public

\section{Administrator as a}

Guardian and/or conservator for mentally incapacitated Individuals when there are no family members that are willing, available, or suitable to serve. Guardian/ conservatorship is a monumental responsibility, which can be overwhelming for relatives. Public administrators will occasionally be appointed in cases where physical or financial abuse has occurred and family members themselves are the perpetrators. As in the case of the older ward/protectee, who may be suffering from Alzheimer's or another form of dementia, he or she may have outlived any relatives, or, the family members themselves may be elderly and unable to serve. A common appointment of the public administrator as guardian/conservator is for wards with mental illnesses. In these situations, family members may have already been involved in trying to help the incapacitated loved one and have become "burned out". Persons with mental illnesses can be quite manipulative, especially with parents and siblings, which can sidetrack the ward's recovery process (Greene County Public Administrator, 2013).

Public Administrator offices in the State of Missouri are "fee offices, meaning that fees are

charged for services (usually based upon the time invested by the PA and upon the client's ability

to pay). Fees must be approved by Court Order" (Greene County Public Administrators, 2013).

All of the Public Administrators report that they are often unable to collect any fees because their wards do not have the funds to pay.

Greene County Public Administrator's websites state that some of the major responsibilities of the Guardian/Conservator are

Client Advocate - for housing and living arrangements, employment and day training,entitlements and benefits, religious rights and for good medical care. Further, an important aspect of advocating on behalf of the ward/protectee is the ongoing assessment of the need to continue guardian/ conservatorship.

Restoring the ward's rights is known by the legal term, restoration. Surrogate Decision Making- there are two suggested principles (per the National Guardianship Association) to be considered when making Decisions for the client: Substituted Judgment - which asks the question, "What would the ward/ protectee have wanted for himself?" This principle best protects the autonomy, values, belief and preferences of the ward. Principle of Best Interest - used when the guardian/conservator is unable to determine what the ward would have done in a particular situation (which is often the case with public administrator clients who have no relatives or friends around who can give this information and the ward himself is unable to communicate his desires because of the severity of his illness). Informed Consent - regardless of which principle of decision-making is used, it is imperative that the guardian/conservator makes it using what is called informed consent which requires full disclosure of the facts. Informed consent involves using 
a systematic set of criteria. Further, the guardian should not make decisions "in a vacuum." Information may be needed from family members, doctors, nurses, an ethicist, the ward's minister, etc. Also, the guardian needs to determine if a court order is required. Coordinator and Monitor of Services - it is essential that the guardian/conservator develop and maintain a working knowledge of the services, service providers and facilities available in the community and to stay informed of any changes in these resources. The guardian should be in control of the plan of medical and personal care for the ward. The plan of care is developed with ward's input (when possible) by first assessing his/her needs and strengths and determining his/her goals. Then the guardian contracts with service providers to meet those needs and assists in the goals. The guardian/conservator must continually monitor the ward's progress as well as the effectiveness of those services. (Greene County Public Administrator, 2013).

All three of the Public Administrators interviewed stated they took the position when the previous Public Administrator was retiring. They were all females over 40 years old. They appeared fairly homogenous regarding social and educational backgrounds. However their professional backgrounds were markedly diverse. Each put different weight on their professional and personal experiences when it came to dealing with the situations their position required. While they unanimously agreed there was no college degree to prepare them for this job, they all described their role as an "advocate" for their wards.

Tammy Bond is in her third term (ninth year) as Public Administrator for Bates County. The population for Vernon County is 21,159 (U.S. Census 2010). She has the highest, per capita, number of wards compared to surrounding counties due to the previously location of the asylum and the Nevada Habilitation Center.

Tammy Bond stated that her background

is in banking and finance...(and) a title company. But one of the biggest things that I feel like prepared me for this job was taking care of my mother in her later years of life starting with dementia...downsizing from a home to an apartment, then to assisted living, then more assisted living and then finally to a nursing home. And then she got neglected in a nursing home and lost her leg so that was a very extreme, eye-opening experience.... and then to the point where my sisters and I were going and feeding her a meal, once a day, to make sure she was getting her nutrients and stuff like that (2013). 
Tammy Bond added

I don't have really any background in social work or anything like that. I just call it common sense... Sometimes I have to sell real estate so my background helps me...but nothing can give you the, you know, what to do in this job until you do it. You have no idea what to do in this job until you do it. I think common sense and compassion is the most you can do (2013).

Barbara Davolt has been Public Administrator for Polk County since 2003. Polk County has a population of 31,137 (U.S. Census, 2010) with 74 wards of the state. Polk County has the lowest, per capita, number of wards. Also in her third term, Barbara was born and raised in the county she serves. Prior to being elected as the Public Administrator she worked as the probate judge's clerk for six years, handling all of the guardianship cases in the court system. She believes that her background in the court system helped her the most with her current position. She describes her role in the lives of her wards as

an advocate and kinda a mediator and buffer-a lot of times among family members. And then just advocate for their healthcare needs, protecting their assets, a lot of times you're protecting them from their own family (Davolt, 2013).

Barbara explained that working with family members is one of the more challenging aspects of her job. She discussed how her clients are "almost better if they don't have family...because they've financially exploited this individual. They're the reason that someone stepped in and filed for guardianship" (Davolt, 2013). Barbara discussed how her roles as a public administrator protects her wards from being exploited, physically abused and mistreated. Barbara noted, that when it came to obtaining services for her wards "guardianship with a public administrator is viewed very differently that guardianship with the family" because families “don't understand the system. And they don't know how many rights they have as that person's guardian" (Davolt, 2013). 
Sharon Cumpton ran for the position of Public Administrator for Bates County when her mother-in-law was ready to retire in 2002 . The neighboring county of Vernon County, with a population of 17,049 (U.S. Census, 2010), it has 70 wards of the state. She has a background in medical care but stated she relies on "common sense" when making decisions for her wards (Cumpton, 2013). She added that she "them as like they were my own family" (Cumpton, 2013). $\underline{\text { Staff }}$ Staff is present at this facility twenty-four hours a day, seven days a week. The staff works on shifts from 7:00 a.m.-3:00p.m., 3:00 p.m.-11:00p.m. or 11:00 p.m.-7:00 a.m. There is one staff member on each shift except for the 7:00a.m.-3:00p.m., where there are two staff. This facility employs nine staff who are Certified Medical Assistants (CMA's), a nurse (for consulting) plus a maintenance worker (who divides his time between the corporation's other facilities). CMA's are qualified to pass meds and perform other services such as taking vital signs and performing some medical treatments. The staff works directly with the residents to carry out the objectives and goals of the RCF and are responsible for supervising the daily living activities (DLA's) of the residents. Some residents also receive physical assistance from the staff with bath and body care.

Rhonda is the most senior staff member and has been employed with the company that owns this facility 14 years. One resident described her as "the enforcer". Her demeanor toward the residents can be somewhat abrasive and unsympathetic, at times. One male resident explained to her that his friend died unexpectedly over the weekend. When the male resident expressed a desire to go to the funeral she responded "You wanna do things but you won't get out of bed!" When a young mentally retarded male resident attempted to make conversation with her she 
replies "I'm not gonna answer any more of your questions today! I've got paperwork to do!" then hastily exits up the stairwell.

Another young male resident was arrested for driving his employer's truck at the request of the employer. He was stopped by the local police department, arrested and taken to the county jail. After the Administrator appealed to the court on the residents behalf the charges were dropped. Rhonda believes episodes such as this reinforces irresponsibility of the residents. She was opposed to this resident getting "off scott-free" and says

that is a lot of these guys problem, in my book. If you destroyed something, what happens to you? You go to jail, you pay it back, you get a felony. He has a felony but since he lives in a RCF because he has a mental illness, they don't have to pay anything back. If you go to jail you lose everything because you can't pay your bills and then what happens is they end up in places like this. And it all gets swept under the rug. I think everyone should be accountable.

\section{Administrator}

An Administrator licensed with the DHSS for a residential care facility is

a person...designated as administrator/manager who is either currently licensed as a nursing home administrator or is at least twenty-one (21) years of age, has never been convicted of an offense involving the operation of a long-term care or similar facility and who attends at least one (1) continuing education workshop within each calendar year given by or approved by the department. When used in this chapter of rules, the term manager shall mean that person who is designated by the operator to be in general administrative charge of a residential care facility. It shall be considered synonymous to "administrator" as defined in section 198.006, RSMo. and the terms administrator and manager may be used interchangeably (DHSS, Rules, 2013).

In addition to many other responsibilities, the Administrator is responsible to

assure compliance with all applicable laws and regulations. The administrator/ manager shall be fully authorized and empowered to make decisions regarding the operation of the facility and shall be held responsible for the actions of all employees. The administrator/manager's responsibilities shall include oversight of residents to assure that they receive care appropriate to their needs.

The Administrator at the RCF, is also a family member of the owners of the facility. She also serves as the Administrator to the owners' other Independent Supported Living (ISL) homes for 
the developmentally disabled and mentally retarded. The Administrator is highly energetic and relates to all staff and residents on a personal level. Many of the residents at the RCF call her "momma" (unless she is not around, then a few call another older female resident "momma"). $\underline{\text { Visitors }}$

Visitors are infrequent at the RCF. Any individual entering the property is viewed with curiosity by all present. Inquiries are made to the identity and purpose of the visitor to discern if the visit is official-a state agency coming for an inspection or investigation of a hotline.

Residents may invite community members into the facility without any requests for permission from the staff. However, community members are infrequent visitors. The only visitor I noted during the observation times was the husband of a staff member who had befriended a resident through a mutual employer. The other visitor came under different pretenses. The nature of the relationship between the male visitor and the H.F. was uncertain but it appeared the two had met in the local community. His behavior and conversation implied that he was unaware of her current living situation or mental health diagnoses. The visitor appeared puzzled about what to do when H.F. led him behind the vending machine and told of her plan to have him help her with an elopement. The episode of her whispering and reprimanding the male visitor for not doing the same, lasted several minutes during which he tells her "You can stay at my house if you want to" to which she replies "Can you be here at 3?" He hastily leaves. On the following day the Administrator stated there were no elopements. However, she did say there was one the day prior to that but he/she "didn't get too far...not past the street".

Family

The residents' interviews reported minimal family contact, at most. Two of the three reported no family contact. The third said her daughters had come to see her within the past month but she 
"rarely gets to see them most of the time." During observation I noted one occasion where a male resident had an older female visitor which appeared to be his mother.

The public administrator's all reported that wards often:

have no family. Some have family that don't come but every two or three years. Some come at holidays... and they always don't have the money to go... a lot of them are paycheck to paycheck families. Not a lot of money involved. Not a lot of people that are stable... some of them hold jobs but some of them are hard pressed to make money last "til the next paycheck. Now sometimes their families spent all their money...they dump them into a nursing home" (Cumpton, 2013).

Another female resident was recently reunited with her daughter after 25 years of estrangement.

However, the staff reported the daughter has not returned recently to visit the mother but at the beginning

it was all great. The daughter was buying her all kinds of stuff, cigarettes and this and that. So when she went home last time, she was going to take her for 4 days, an extended period of time, and they didn't even make it a day. When she went to Springfield, to the city, when she would go outside and sit in the little yard in the subdivision, everybody made her nervous and she asked her daughter to bring her home. And the daughter was clearly upset about having to bring her back. I don't think she's taken her home or called her that much since [the resident] said she didn't like how she couldn't go outside. She came home because she couldn't go outside much.

Interactions with family members can be inimical. All public administrators presented stories of wards being abused and neglected by family members prior to guardianship. They all agreed that their involvement arose because the family either abused or neglected its family member. All of the public administrators believed that when they make decisions for the individual it "works out much better" (Cumpton, 2013). However, one guardian stated she believes, that some families have good intentions. They "put them in the nursing home and they can't stand to see them so they don't come back and they don't answer phones" (Cumpton, 2013). Barbara Davolt explained "you have less families wanting to take care of their own... a lot of times (we're) just a dumping ground" (2013). 
During my observation one middle-aged male resident had a female visitor that appeared to be his mother. The female visitor appeared very uncomfortable and the interaction with another female resident only heightened her discomfort. The female resident confronted the male resident and his mother as they were walking down the hallway toward the living room to exit the front door.

Residents were able to keep in touch with family members through telephone conversations. Residents could use the landline telephone in the medication room or their own personal cell phone, if they had one.

\section{The Community}

The Administrator discussed how, before the current owners of the RCF took over the facility, it had a bad reputation in the community. The current Administrator discussed working in the community to improve relations. The Administrator reported that local churches presented the greatest problems for the facility. Although residents of the facility were welcomed at local churches, the churches were ignorant about the issues these individuals faced. Residents would portray themselves as victims of unjustly violations of freedom and as victims of abuse and neglect. The Administrator recalls one recent incident between a male resident who had lived at the facility for more than 10 years and an elderly woman he met at church. The male resident told stories of abuse and neglect at the facility. The elderly woman assisted the male resident with diverting his social security check to another location then securing him a HUD apartment. Within two months the male overdosed twice and arrived at the local grocery store wearing nothing but a t-shirt. The church lady begged other church members for support and assistance but, unable to secure timely assistance, the male was sent to an in-patient psychiatric facility and 
did not return to the RCF. The staff tells of another more recent incident with the male resident who

goes to church and he tells them people that the only thing we feed him is peanut butter and jelly. You could have spaghetti, you could have seven different things on the menu and he will refuse everything and says he doesn't like it and ask if he can have a peanut butter and jelly sandwich so I'm like yeah, 'I'll fix it for you" cause that's the alternative if you don't like the food. So they'll have something to eat. Then he goes to church and says all we feed him is peanut butter and jelly.

The Administrator explained that she works with community members and says "we've even went and spoke in front of the church".

The facility not only had to struggle to regain acceptance in the community but also with the agencies providing funding and support. When considering the effects of her efforts over the past 14 years she says

we have acceptance. In 1999, No. Because this place, it was under a 35 page ordeal, when we took over from the previous people that had it". And there was all kinds of issues. But we didn't know that when we took over. There was only 15 people here. So then we got it to capacity and then we got the Certificate of Need. But it took years to get a good reputation because it didn't have one. There was a lot of mental strain.

Their efforts have paid off. They are well respected among Public Administrators and are considered a first choice for placement of a ward when if there is an opening. 


\section{CHAPTER SIX \\ Findings}

The normalization principle and its human management implications are often misconstrued or misapplied. Each of the guardians interviewed used the term "normal' several times. However, when inquiries were made about what the word 'normal' meant to them they often discussed wanting their wards

to have a good life...I know they're never going to be, per se, normal, but likeable... when people are going to like you and not hate you.... and the better you do the more privileges you get...you get to go to the party or you get to go fishing...the more you can go home or could go to work...go to the whatever...it's that the rewards that they can get" (Sharon Cumpton, 2013).

Here, participation in activities like going home or going to work is considered a reward for good behavior. The burden is placed on the mentally ill to conform his behavior to the norms of society.

One Public Administrator discussed her efforts to find employment opportunities in her community

the developmentally disabled, we can get them a few odd jobs. A lot of them volunteer at thrift stores and hang clothes up. They don't get paid but they may earn a quarter credit or something like a free blouse. But it's really hard to find work for them (Bond, 2013).

The burden is should be placed upon society to create socially valued roles for all of its participants. Instead, disabled citizens are expected to conform to the standards of the rest of society. One male with a mental illness and mental retardation diagnosis discussed working for a kitchen small appliance factory in a nearby community for two weeks before

they fired me because they said that I was too slow on the assembly line. They said the only thing they liked about me was 'redo work' but they didn't have enough redo work to keep me busy everyday so they fired me. They said I wasn't really fast enough on the assembly line. 
A majority of the work that the mentally ill and developmentally disabled are able to secure are through sponsored programs. These "sheltered workshops" and other programs are supported through state and federal funding. There are very few programs like this available, but more importantly, they do not incorporate the disabled individual into a workplace with other society members. Again, the individuals are segregated from society in their workplace.

As with Normalization, Social Role Valorisation is often misunderstood and misapplied. Most of the individuals interviewed implied that having a job or participating in community activities is a privilege for good behavior. One guardian explained "the better you do the more privileges you get, the more you get to participate in things...the more you can go home or go to work." Another public administrator said

and so if they're doing really well and they're thinkin they might want to work well then I'll find a facility closer to a workshop so they can go to work if they're doing really well where they're at... some of them don't want to work a lot but I like them to have a reason to get out of bed (Cumpton, 2013).

One Public Administrator noted

there's no housing for them so they go rent an apartment and get kicked out. And once you've been kicked out of low income housing you're blackballed everywhere. They can't afford to rent a decent apartment. And then if you do find them something-I wouldn't live in it and why would I want my client to live in it? (Bond, 2013).

The program of deinstitutionalization is still in progress. Public Administrator of Vernon

County, Missouri, Tammy Bond currently struggles with the closure of the Nevada Habilitation

Center in 2012. She reported that during her second year in office

In 2012 is when they (Department of Mental Health) started saying it's gonna happen, they said it'll be done by 2012 . There are no patients living on the campus here locally. Now, they did, we had a choice when they were put out into the community where we wanted them to go... We fought tooth and nail not to get this because I think there's a huge majority that can live in the community with good supports without any problems. But there's those few that we've 
tried...When they were at the Hab Center there was so much oversight than there is living in these individual homes... But there are just some of them that are so fragile that it's really scary unless you know those people taking care of them. You know these positions are not high paying positions... But when you get into these private providers...they try to do the best they can... it's harder for them to keep good employees (2013).

The government has increasingly shifted the responsibility of their housing needs to private organizations. As one Public Administrator put it “DMH doesn't want to own buildings and stuff...or be responsible for upkeep and things like that. They don't want the bricks and mortar" (Bond, 2013). She added, the state does not want the responsibility any more. They've privatized all the placements... Everything is going privatized. Well maybe that's great for them but for those private people-they don't have to take my clients. So when you've had somebody in 5 or 6 RCF's, where do go with them? They don't want the responsibility of anything going wrong with a lawsuit (Bond, 2013).

When the government began closing facilities they made no provision for the construction of new ones. As a result many mentally ill live in housing that is not designed for them. One public administrator discussed how the city she lived in, Nevada, had five new built RCF's. After further discussion she stated that the buildings were originally designed for the elderly but are now being used as RCF's for the mentally ill. When asked if they had the appearance of a nursing home she stated

Yeah, kinda, in a sense. I mean it's a room the size of this office (about $8 \times 14$ ) and you have two people living in it. And they go down to the cafeteria and get their meals and go back to their room or they've got a couple big dining setting areas (Bond, 2013).

She further explained that "there's no place for the mentally ill population to go to. You're getting this population group right now that is 20 's, 30 's, 40 's that have this mental illness but there's no facilities to go into to get help...there's no housing for them" (Bond, 2013). And even 
in the facilities that are available (i.e. RCF's), individuals with difficult behaviors are hard to secure stable housing.

When Public Administrators were asked about how important the physical features of the buildings their wards live in they all responded similarly. When one was asked if there were and physical characteristics she like about this facility she responded "I wouldn't want to live there. Would you? (I)t's an old building. It's an institution. I wouldn't want to live there" (Davolt, 2013). Another Public Administrator stated

I'm not looking for the bells and whistles, or the look of the building. I'm looking for the staff and the care because that's what it's all about. I mean you could go to the nicest place in town with the fireplaces and the grand pianos but that doesn't mean that they're gonna get the care they need (Bond, 2013).

This Public Administrator, discussed a particular facility in the area. "It's a big, old, two, threestory house. I, myself, would probably not want to live there" (Bond, 2013). The third Public Administrator stated "I don't look at the building as a rule. I know buildings are really well worn with mentally ill patients. They are not taken care of. No matter how hard you try they're not the prettiest buildings" (Cumpton, 2013). 


\section{CHAPTER SEVEN \\ Discussion}

Dante Alighieri wrote in Inferno "we to the place have come, where I have told thee... Thou shalt behold the people dolorous...who have forgone the good of intellect" (1400's/2006). The residents of the RCF were a case-mix of individuals with a variety of diagnoses. The diagnoses ranged from serious mental illnesses, mental retardation, traumatic brain injury, cerebral palsy, etc. In addition to these residents, the facility accepts the indigent-as long as they have the ability to pay. The residents are haphazardly thrown together in this absurd situation to share their daily experiences. Trapped within the walls of the RCF, they are left to struggle together with more environmental demands that could peaceably be absorbed. Like the characters in tragicomic play, they must remain together-each one inescapable from one another. And yet the absurdity of their situation never occurs to them.

Although there is a conspicuous discrepancy between their aspirations and the reality of their situation, they remain unable to see the absurdity in it. The residents are unable to take the crucial backward step to see their situation from outside themselves. Unable to survey their situation, they cannot begin to question their seemingly inescapable situation and are forced to painfully re-enact their daily existence. Their senses are dulled by heavy doses of medication and they are trapped in a prison of their own complacency. They are left unable to reflect on the significance of their lives and imagine some change that would remove the absurdity. They remain mentally paralyzed, even catatonic, at times.

The residents interviewed in this study expressed a generalized sense of a lack of control over their environment and have become profoundly passive in their efforts to escape their situation. 
The residents expressed their situation as inescapable and independent of their efforts to escape similar to the traits of Learned Helplessness (Seligman, Walker \& Rosenthan, 2000).

The cycle of feelings of total helplessness and self-defeating behavior are evident in their statements throughout the interviews. They saw themselves as stuck in a situation without any control and believed any actions they took would not make a difference. They understood that the outcome of their lives was not contingent on their behavior but was in the hands of other decision makers. Their expectation that future responding will be futile undermines their motivation to respond and produces difficulty in seeing that outcomes are contingent upon responding. Although they discussed attempts to improve their situations they were constantly reminded of their failures by the RCF staff members, guardians, and Administrator which maintains the tensions between the resident and society.

The residents are examples of individuals which have failed to live up to what society has effectively demanded of them, and yet remain largely unaffected by their failures (Goffman, 1961). Despite the fact that their connection with the outside world had already started to decay, the residents remained insulated by their alienation, protected by identity beliefs of their own, and feel that they are a full-fledged normal human being despite the many steps society has taken to prove otherwise (Goffman, 1961). They react by focusing on correcting these perceived minor failings in an effort to restore their identification as full-fledged members of society. They attribute their current situation to only minor failings with which other normal human beings struggle.

In an effort to create and manage an image of integrated self, participants develop ways in which their interactions seem meaningful and reasonable. Some residents offered unsolicited information regarding their educational or employment backgrounds, familial involvement (or 
lack thereof) current involvement in activities, knowledge regarding various medical diagnosis and medications, and therapeutic interventions. D.A. perceived his inability to secure stable housing, meet his medical and social issues as an inability for normal people. R.C. continues to focus on securing appropriate familial relationships and H.F. attempts to prove her ability to manage her finances by managing the residents' coffee fund. However, they are continually reminded of their failures by the RCF staff members, their guardians, and the community.

In spite of their ambivalence about their group identity they make efforts to establish loyalty to their membership within the facility. Members developed a lingo understood by all participants. They used agreed upon terms such as "passing meds", "med room" and the "sign out." Members also participate in following agreed upon implicit and explicit rules and reminding others of their obligations to follow these rules. These activities reinforce their group solidarity by providing them with feelings of belonging, identification and emotional attachment while shielding them from the rejection of society.

Residents of RCF's may question whether their membership in the RCF world is even justified. Surely, they would say, based on their interactions, they are clearly more capable of providing for themselves, their capabilities have been overlooked, or they have been wrongly accused or their intentions misunderstood. H.F. minimized her behavior and presented situations that, at the very least, shed a neutral light on her. She portrayed herself as very competent and knowledgeable in everything from child care, insect control and extermination, money management and medical terminology. They are able to uphold this impression of their self, due to limited contact with the community.

All residents interviewed in this study openly expressed avoiding social situations in the community. The residents experience tensions about their presence in the community and past 
problems regarding behaviors of other residents. One resident stated "I don't like going out into the community because I don't like associating with a lot of people". Another resident described only going out into the community with a staff member to do Community Integration activities. The third said she goes "to the library and that's about it".

The Built Environment

For these residents, social situations cause anxiety by increasing the chronic feeling of the worst sort of insecurity (Goffman, 1961). Interactions with community members force them to confront their deficiencies which led to their current situation. By avoiding, or severely limiting, contact with community members they are able to sustain their interpretation of their character and social identity. The residents of the RCF refrain from interacting within the community and isolate themselves within the facility.

It is estimated that people spend more than $90 \%$ of their lives within buildings (Evans and McCoy, 1998). This research study found this especially true for the residents in this RCF. The world within the facility designates the level of face-to-face encounters members must engage in. The boundaries of the RCF- it's walls, outside grounds, property lines, and community, etc. force upon the residents and staff the level of contact that will be required to participate in on a daily basis. Several residents could only minimize the level of contact by attempting to isolate themselves in their bedrooms and/or sleeping excessively.

All of the residents interviewed described living in this RCF as "too hectic" and "stressful". The symptoms of stressful reactions described by Chorpita \& Barlow (1998) were evident in the residents' statements and behaviors.

My study identified several areas of environmental stress in the RCF and overlapped with the taxonomy developed by Evans \& McCoy (1998)- crowding, and the after effect, noise 
(Stimulation), lack of stimulus shelter (Restorative), absent or vague behavior settings

(Affordances), a disruptive circulation path (Coherence) and lack of control over space (Control).

The specific design elements were identified as significantly contributing to stress within the residents of the RCF.

Throughout the observation times there was a constant flow of traffic throughout every room and more than one hundred interactions were recorded in less than a two hour period.

The residents of the RCF in this study expressed a lack of privacy or a place to go that provides them with a stimulus shelter. In an effort to manage the barrage of activity one resident described spending about 20 hours a day in her room. But this gave her little relief due to her two roommates and her bedroom directly inside the front door which "slams all day long." The residents had no place to go that provided them with a quiet place and shield them from the barrage of activity within the facility. Without a quiet place to go the residents' are deprived of a quiet place to go to abate the stressful environmental demands of the RCF. Without a stimulus shelter the residents are confined to a stressful environment and remain helpless in changing their situation.

Residents' freedoms are restricted due to tensions within the community. The Administrator discussed how the facility "had a lot of trouble in the past". The Administrator acts as a mediator when tensions arise between the residents and community members. The Administrator discussed her efforts to improve relations between the community and the facility. However, the result of the tensions between the residents and the community has resulted in restrictions for the residents. If a resident "gets into trouble" in the community he could be restricted from leaving the grounds of the facility. Therefore, the community is unable to provide the residents with resources to reduce cognitive fatigue and attenuate stress. 
Without these resources, the residents remain overstimulated and unable to offset some of the stressful impacts of their environment. With their coping skills already compromised by their mental illness, they remained unable to deter aversive stimulus which interfere with optimal behavioral functioning.

The availability of private spaces are also instrumental in providing residents with a resource for attenuating stress by balancing environmental demands with personal resources. Private spaces are absent as all areas are shared by at least one other resident therefore, residents are forced to display all behavior publicly.

Although bathrooms were built in many of the rooms when the hospital was constructed in 1929, few are in working order today. Two rooms currently have their own bathrooms which serve about six residents. All other residents must use the shower room and restroom in the corridor. Showering and restroom facilities are prevented by state law from having locks.

During observation one naked female resident was exposed to this researcher and other residents in the hallways. Additionally, many of the male residents used the toilet without closing the restroom door and any passerby in the corridor could be exposed to another resident urinating.

Bedrooms are also shared by at least one other resident. Many rooms are shared by three to four residents. One resident explained the efforts she takes to dress everyday without being exposed to other residents by dressing in her closet. A lack of privacy and the resulting fear of exposure to other residents cause stress for residents by depriving them of control over their own bodies.

Overstimulation can come from a variety of environmental sources and cause a myriad of behavioral effects. In studying early childhood development, Wachs \& Evans (2009) found that 
higher levels of residential density and chaos were inversely related to performance tasks. Density measures are quantitative assessments of the number of persons per spatial unit. The measure most often employed is the number of persons per room.

It might be expected that as density increases experientially there is an increase in noise (Heft, 1984 as cited in Wohlwill \& Heft, 1991). Noise "can be studied as a type of environmental stimulus in terms of its impact on behavioral functioning, well-being, etc., that is a standard problem for psychological research conforming to the $B=f(E)$ paradigm" (Wohlwill, 1984). Wohlwill concluded that the problem of noise as an environmental issue serves as an aversive stimulus and interferes with optimal behavioral functioning (1984). Exposure to noise has been empirically linked to both auditory and non-auditory effects. Non-auditory effects of noise include physiological detriments (increased heart rate or blood pressure), low motivation, and poor cognitive or attentional performance (Evans \& Lepore, 1993; Evans, 2001).

The spatial organization of the facility designates the circulation paths of the users. The argument has been made that circulation paths should be separated from behavior settings yet should allow and encourage movement between settings in order to stimulate exploration and cognitive development (Moore, 1987).

In most American homes a living room is used for relaxing, lounging around and watching television programs. However, the front door at the RCF in this study is heavily used and has developed its own squeaking sound as it is opened and closed numerous times every hour. The front door provides the only entrance to the building from the front of the building and leads directly into the living room. The living room provides access to the heavily used dining area (where the staff are located in the 'med room') and the corridor-which provides a variety of options. 
The circulation path created by the front door and interior spaces provides the residents with mixed cues about the expected behavior in the setting. Without being able to predict what type of behavior is expected the resident experiences frustration because he or she cannot determine what sort of behavior is appropriate in the specific setting. The meaning of the living room is lost and the residents have difficulty making sense out of it. The result is conflicting signals about the purpose which heighten the residents' stress level.

Psychologist Donald Norman states that when "a building user cannot see what or how something is the space functions or when confronted with cues about purpose or use which are vague or in conflict, human reactions are likely to encompass frustration, annoyance, and, on occasion, even hostility or helplessness" (1989). Ambiguities or misinformation about functional meaning of interior elements can result in stress due to disorientation caused by vague or missing cues or use of too many competing cues. Clearly legible behavior specific spaces are necessary so that the residents can move from one space to another with a clear intention about the behavioral expectations of that space. When the legibility of a space is clearly defined the users can behave according to the expectations of the space. When they are able to do this is it gives them a sense of accomplishment and competence. Spaces that provide a clearly discernable function and provide feedback to the residents regarding its purpose are very limited or absent in the RCF in this study.

The dining area in the ell, directly behind the living room, underwent several changes over the years, is heavily used throughout the day and evening despite its lack of comfortable seating. The seating in the dining area are booth-type tables and benches, all of hard surfaces, lined up along the outside wall. Residents use this area not only for consuming meals but also for 
reading, coloring, craft projects and visiting with other residents however, the appeal of this area appears to be the presence of the "med room" within the dining area.

The med room lies directly inside the dining area when entering from the living room. The med room is where the staff members remain for a majority of their shift. Rarely was a staff member observed outside of the medication room during the observation periods. Staff members spend a majority of their time in the med room "setting up meds", completing paperwork or "charting" and sorting through various documents, including incoming facility and resident mail. When the residents require assistance with any of their various needs (receiving mail, making telephone call, obtain weekly spending money, making appointments, personal issues with other residents, or assistance with facility issues-i.e. laundry, cleaning supplies, or maintenance) they must stand in the dining room and wait for the staff to assist them.

Throughout the day residents can been seen lining up in the dining room to wait for assistance from staff members or be present for their multiple daily rounds of medications. The combination of the medication room with the dining room creates conflicting cues about the behavioral responses of the dining area.

The conflicting cues and feedback about the behavioral expectations of the place undermines the residents' motivation to appropriately respond and organize their behavior accordingly. This reinforces their passivity and causes them stress because they are unable to appropriately respond to the behavioral setting. The result is a lack of competence they feel about the ability to control environmental demands and reinforces Learned Helplessness traits.

Without the features of adaptability, control, freedom, and security of tenure individuals are unable to connect with their environment in a meaningful way. The structure they live in only provides them shelter without the safety and security other individuals enjoy when they make a 
place a home. For individuals living within any type of facility there is a struggle to have a sense of adaptability, control, freedom, and security of tenure. My study found this is especially true for individuals living in this RCF.

The residents at the RCF in this study are encouraged to make the facility their "home" and consider other residents and staff as family members. However, the residents lack the vital features that would enable them to do this. The residents expressed a consistent deprivation of a sense of privacy, adaptability, control, freedom and security of tenure. These deprivations reinforced their understanding of the way the world works and strengthened pre-established Learned Helplessness traits.

The residents in this RCF had little control over their environment. They do not participate in basic activities like meal planning or preparation, doing their own laundry, and have limited choice in planning the arrangements of the home décor.

M. Powell Lawton notes "there is ample justification in theory for exposing tenants to new activities, training them to recognize and exert choices, and even for learning social skills within a planned housing context... by making available both leisure activities and instrumental task opportunities" (1998). This may be as simple as encouraging the residents to plan rearrangements of the home décor, aesthetic spaces and so on.

Residents are not able to determine where they live-this is usually done by their guardians and staff of the facility. As a result, the residents are often removed from the community in which they grew up and away from their families or any informal support network they may have established. Family and social ties are severed by distance and attempts to maintain them become too burdensome. 
In addition, residents' freedom is largely restricted by the heavy doses of medications that result in the resident's complacency with their situation. Many of these psychotropic medications-haloperidol, resperidone, olanzapine, quetiapine, clozapine, and aripiprazole have serious side effects. Very common side effects of these medications to the central nervous system are sedation, agitation, insomnia, confusion, lethargy, and anxiety. In addition, other physical side effects such as seizures, agranulocytosis, leukopenia, leukopenia, neutropenia for which other medications (carrying their own adverse side effects) are prescribed.

Mayer Spivack (1984) explored how an "enriched setting might create an expectation of possible future health. Perhaps a good environment is one... which attempts to do no one any harm". Environment \& Behavior research has contributed widely to the physical environment for a variety of populations (child care centers, school, hospitals, etc.) however it has failed to overflow into the area of mental health. Therefore, no new type of living facility has been developed for them that "support and promote the values, social relationships, and patterns of activities that are dominant in the society at that time (Frank, 1994 as quoted in Schwarz, 1996). Instead the mentally ill live in makeshift environments that are detrimental to their overall health and as a result suffer from a reduced quality of life.

One Public Administrator explained that, in a RCF the mentally ill "have no quality of life... They get up, they take their meds, they go eat breakfast, they go back, they flop down in bed, they watch tv, they get up for lunch. There's nothing...(they're) never gonna learn anything in those...places except to get up and go get a meal and go back to his room and sit...wouldn’t you love that? It would be so depressing" (Cumpton, 2013). The residents are trapped in their absurd situation without the ability to change it. 
Another Public Administrator discussed the opportunity for some "wards" to work in the community and earn money contributes to their quality of life, "it's not the best quality of life, but at least it's some quality" (Bond, 2013). The effects of their physical environment can hardly been seen as therapeutic but, instead, exacerbates their mental and physical health conditions and perpetuates their institutionalization.

Environments for the mentally ill have been abstracted from the guiding principles of the medical model and have led to the misguided development of living facilities for the mentally ill. Based on this study the Medical model described by Canter and Canter (1978) where the resident is seen "as a patient who has an illness which is to be cured" is most evident in the organization of this RCF. The residents of the RCF in this study are bound to the communicated behavioral expectations of the space of the hospital. In the RCF in this study, the daily routines were determined by frequent scheduled medication times and progress in treatment was measured by their "med compliance".

Once we set aside notions that institutions are an inevitable outcome of appropriate societal goals can we consider alternatives and begin to design innovatively. By failing to do this we have created a society in which democracy has come to mean our most vulnerable members feel such a sense of powerlessness and live in hazardous conditions while the powerful live in ignorance of the barbarity perpetuated by their fears.

An alternative to the medical model is the social ecological model based on the assumption that patterns of health and well-being are affected by a dynamic interplay among individual and social needs, the physical environment and the interplay of policies that affect the rules and regulations of the RCF's. 
The relationship between the individual and the larger social and physical environments is a key to the environmental model. The environmental model serves to identify multiple points of possible intervention in public health, to postpone the risks of disease, disability, and death; and enhance the overall quality of life. The environmental model rests on incorporation of research from diverse fields, such as biologic, behavioral, social and environmental sciences.

Use of an environmental model for a therapeutic setting for the mentally ill would result in an overall increase in quality of life through a reduction in their level of stress. A reduction in their stress level would reduce their symptoms and provide them with increased opportunities and an overall better quality of life.

All of the public administrators expressed the need for more government involvement in the care for the mentally ill. Tammy Bond, Public Administrator in Vernon County, discussed her involvement with their local and state representatives. She expressed the need for the county, state and federal departments (DHSS, DMH and HUD) to work together to develop more housing units with on-site services.

When asked about a "best-case scenario" for housing and treatment of the mentally ill she used the example of their local housing authority who worked with DMH(through SWMPRC) and the local CMHC to make housing units available to their clients. 


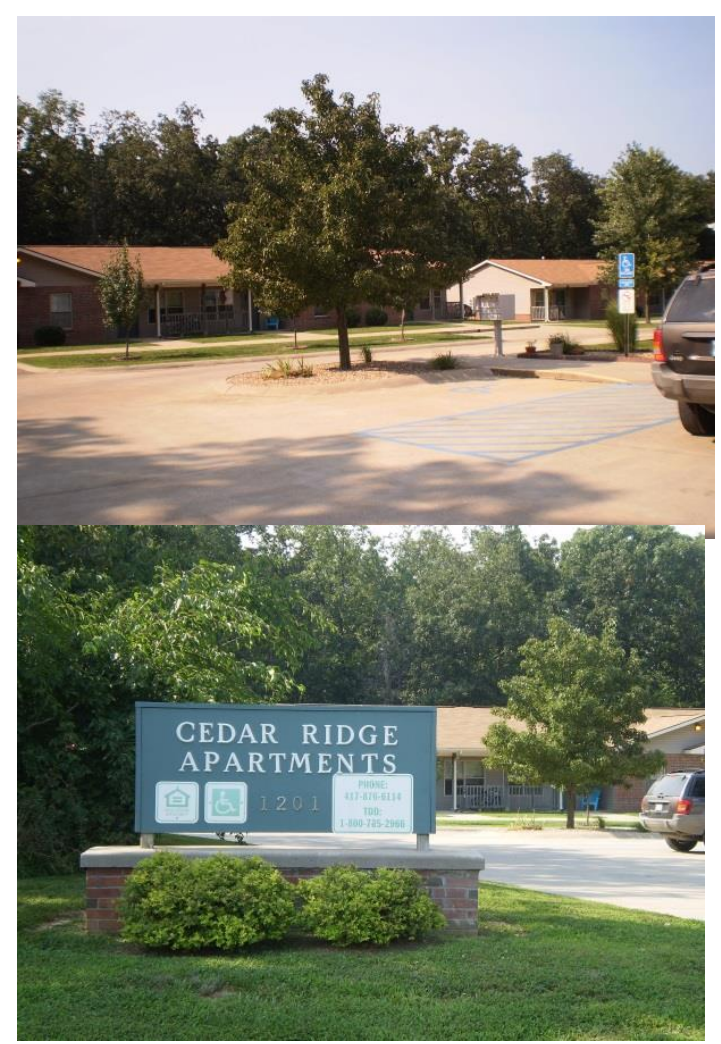

Figures 27 and 28. Cedar Ridge Apartment, El Dorado Springs, Missouri

Tammy described. She described working with DMH, through SWMPRC, to develop

some kind of test program in Nevada that we could have some medication management for a certain set of apartments, but maybe not 24 hours...(so) some of my mentally ill clients, if we could get just that little bit of oversight we could keep them in their apartments. I would be so much cheaper... It's so cost effective to pay a med tech to give somebody meds to keep them out of the $\$ 100,000$ a year behavior ward stay (Bond, 2013).

Evans \& McCoy state "a major weakness of our taxonomy [stimulation, coherence, affordance, control, and restoration] is the lack of empirical evidence linking the design elements we have identified to human health. At present the knowledge base is simply not there" (1998).

The study was an attempt to rectify the lack of knowledge in this area by identifying direct links between the residents' worldview, psychological diathesis, taxonomical environmental elements, and behavioral responses of the residents. In addition, it was able to explore other housing options and programs that may be beneficial to individuals with a mental illness. 
Helping residents realize their efficacy in their circumstances and designing environments to meet their specialized, complex needs may be enough to significantly overcome their illness and help their obtain a better quality of life is a step in the right direction for designing specialized therapeutic environments for the mentally ill. Until then these residents are caught in a cycle of futility which perpetuates their continued residency in a Residential Care Facility.

\section{$\underline{\text { Conclusion }}$}

The mentally ill have suffered at the hands of well-meaning but misguided religious sects, political parties' economic agendas, and by a pharmaceutically induced silence. The needs of the mentally ill population may be strategically distorted by policy makers and the medical profession and rooted in their esteemed ideology. The mentally ill have unique issues and require attention to their specific environmental needs. Long-term care facilities are an offshoot of nineteenth-century asylums. Despite asylums failures regarding their therapeutic aims, they continue to be replicated, only in smaller versions. As an institution, both its physical and social aspects reflect governmental policies and procedures as opposed to a personally meaningful place. They retain their institutional elements and rob their residents of any chance of normalization.

Although Irving Goffman's seminal work regarding institutional settings (1961 \& 1963, see also, Rothman, $1971 \&$ Spivack, 1984) has done well to inform Environment \& Behavior research of the detrimental effects of institutional living, current living environments of the mentally ill have largely been ignored. Canter \& Canter (1979) note "it is surprising that there is a such a paucity of information about the design of therapeutic environments derived from effective research processes... it is almost as if in the need to get on with doing something useful little resources are available for evaluating and studying what is being done". Thirty-five years 
have passed since this statement by Canter \& Canter and yet there remains a paucity of information. While the United States government continues to reduce funding for mental health services there is little hope for funding for mental health research. While the mentally ill will continue to suffer, society, as a whole, will bear the ultimate economic and social price. 


\section{Exhibits}

Exhibit 1. Individualized Education Program

\begin{tabular}{|c|c|c|c|}
\hline \multicolumn{4}{|c|}{ THE INDIVIDUALIZED EDUCATION PROGRAM FOR: } \\
\hline Name: First & Middle & Last & \\
\hline \multicolumn{4}{|c|}{ STUDENT DEMOGRAPHIC INFORMATION (Optional): } \\
\hline \multicolumn{2}{|l|}{ Current Address: } & & Phone: \\
\hline Birth date: / / Age: & Student ID \#/MOSIS\#: & & \\
\hline Present Grade Level: & Resident District Home School: & & \\
\hline \multicolumn{4}{|c|}{$\begin{array}{l}\text { If the child is Not receiving his/her special education and related services in his/her home school or resident } \\
\text { district, indicate below where the services are being provided. }\end{array}$} \\
\hline \multicolumn{4}{|l|}{ District/Agency Name: } \\
\hline \multicolumn{4}{|l|}{ School Name: } \\
\hline \multicolumn{4}{|l|}{ Address: } \\
\hline \multicolumn{4}{|l|}{ Phone: } \\
\hline $\begin{array}{l}\text { Primary Language or Cc } \\
\text { (specify) }\end{array}$ & ode(s): $\square$ English $\square$ spanish $\square$ si & age $\square$ & \\
\hline
\end{tabular}




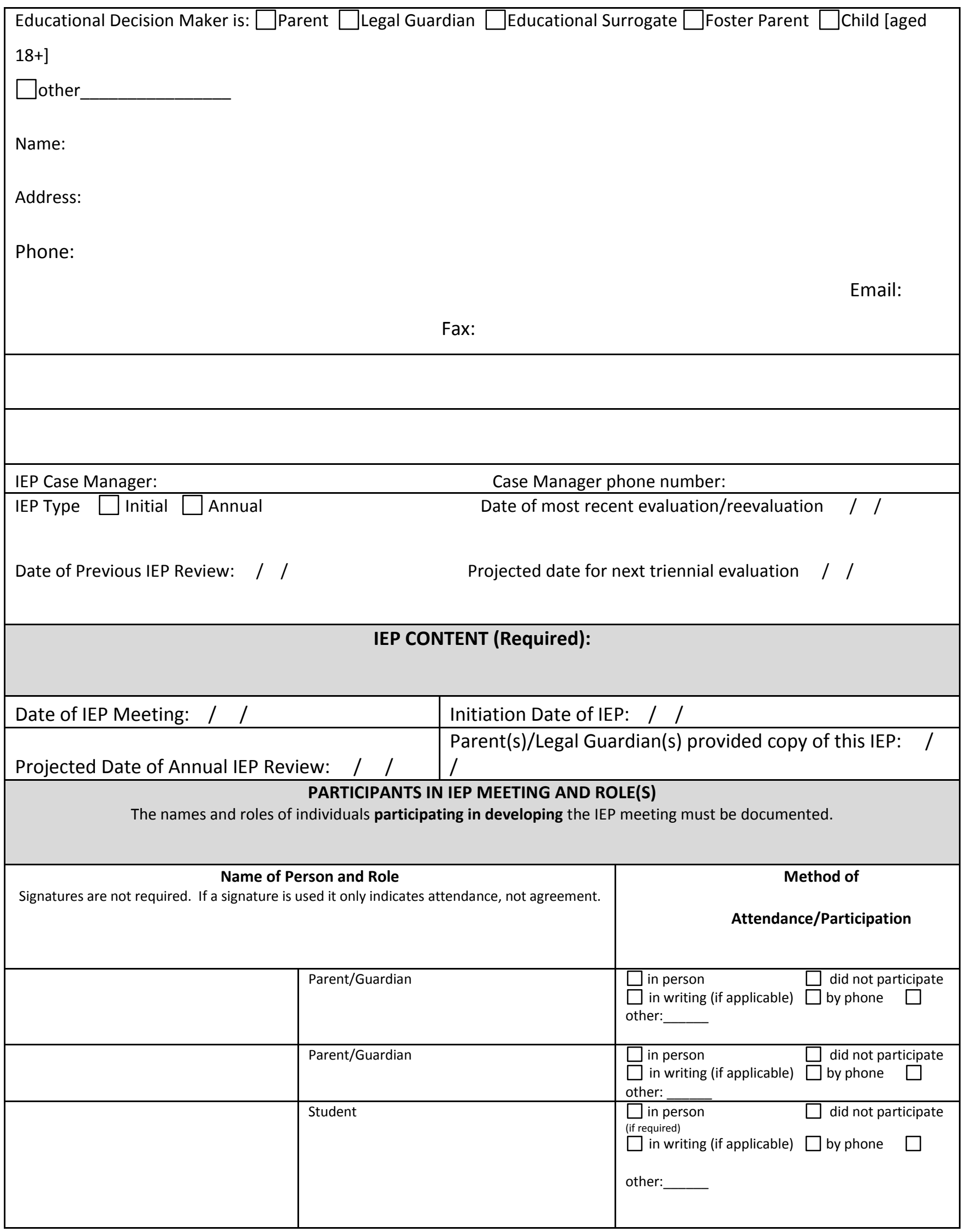




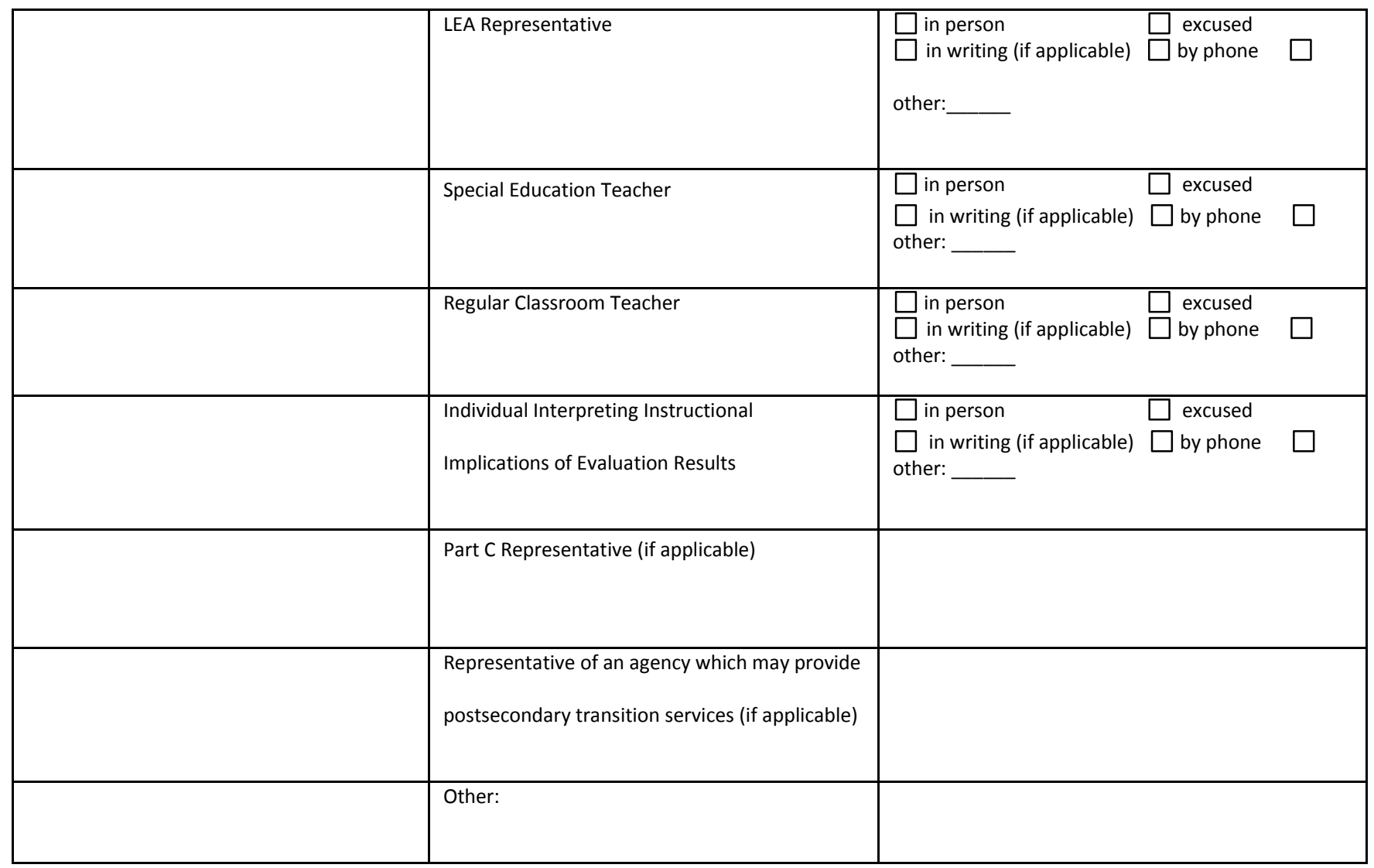


Exhibit 2: IEP Form C-Transition Plan

\section{Form C: Post-Secondary Transition Plan}

This plan was developed considering the individual student's needs, preferences and interests. This plan must be completed, beginning not later than the first IEP to be in effect when the student turns 16 , and updated annually.

\section{EMPLOYMENT (REQUIRED)}

\begin{tabular}{|l|l|}
\hline MEASURABLE & (What work the student will do after graduation from high school.) \\
\hline POST-SECONDARY GOAL(S) & After high school, I, \\
\hline TRANSITION SERVICES & $\begin{array}{l}\text { (May include: instruction, related services, community experiences, the development of employment and } \\
\text { other post-school adult living objectives, acquisition of daily living skills or provision of a functional vocational } \\
\text { assessment that will be provided before graduation to help the child reach the stated postsecondary goal.) }\end{array}$ \\
\hline Responsible Agency/Person & List Transition Services \\
\hline School & \\
\hline Student & \\
\hline
\end{tabular}




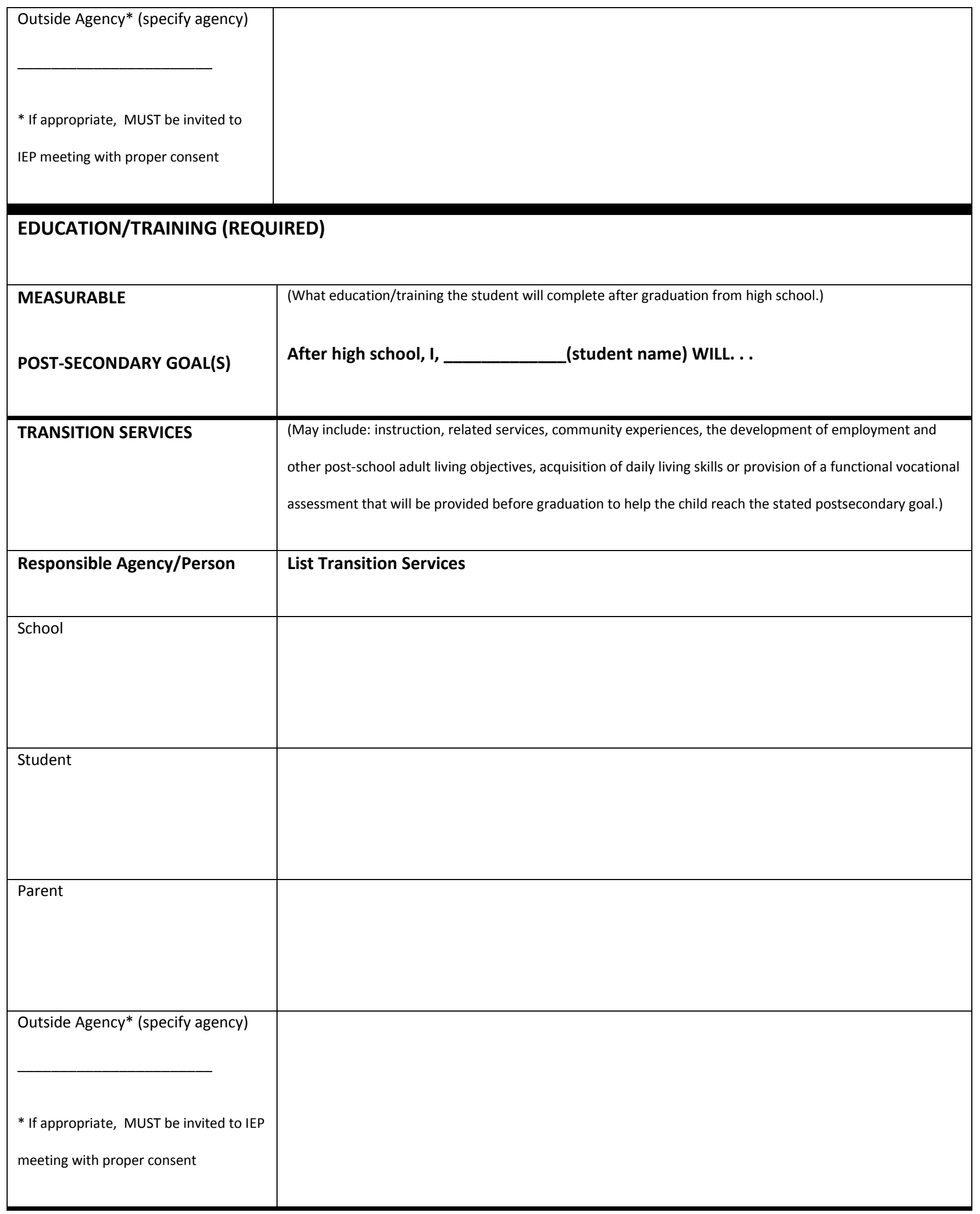




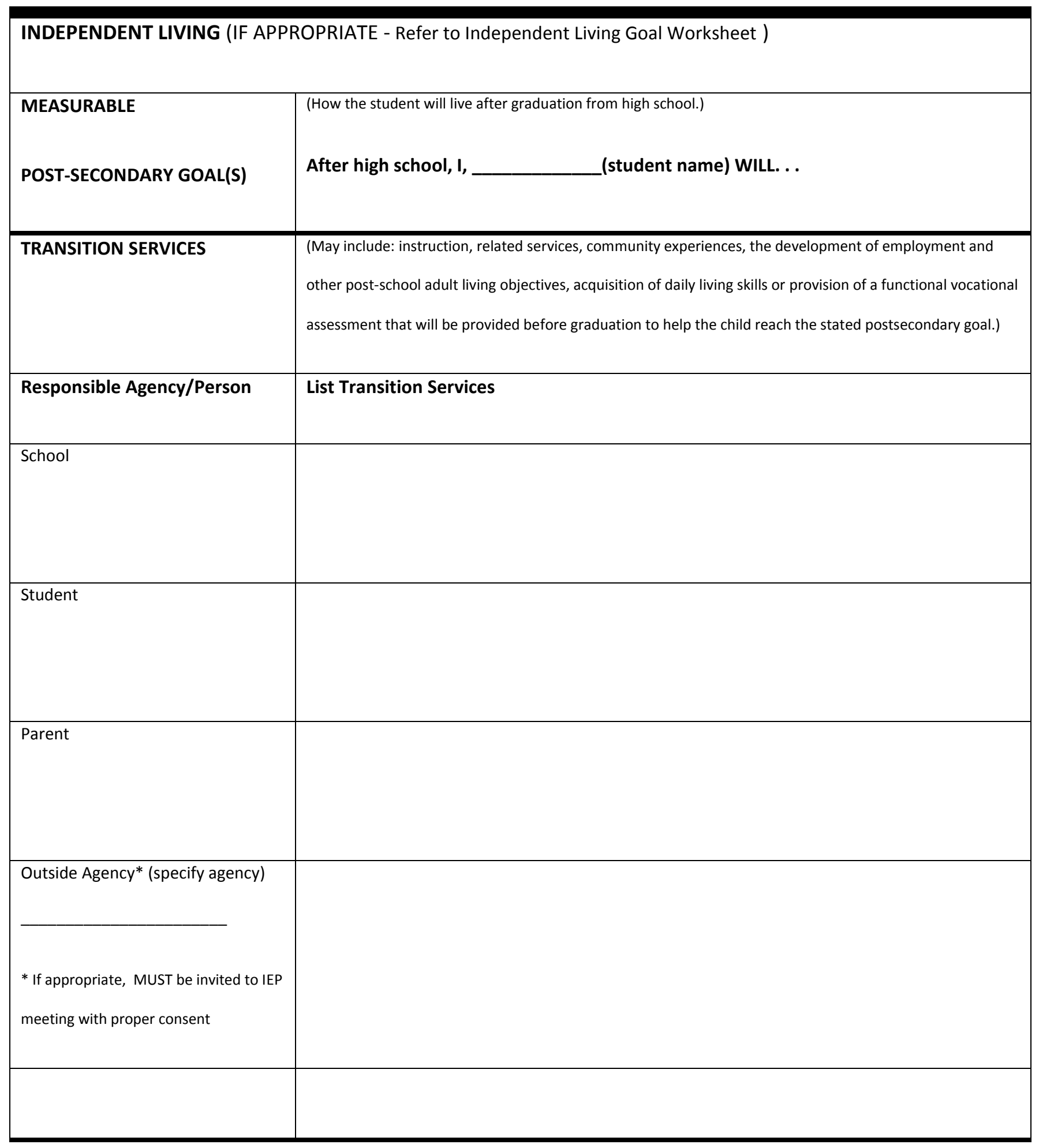




\section{References}

Ahrentzen, S. (1996). Housing Alternatives for New Forms of Households. In C. Hoch, G. Hemmon \& J. Carp (Eds.). Under One Roof: Issues and innovations in shared housing. Albany, SUNY Press.

Alighieri, D. (1400/2006). Divine Comedy. New York: Chartwell Books, Inc.

Altman, I. (1975). The Environment and Social Behavior. Belmont, CA: Wadsworth Publishing.

Altman, I. \& Chemers, M. (1980). Culture and Environment. Cambridge: University Press.

Babbie, E. (2008). The Basics of Social Science Research. Stamford, CT: Thomson Wordsworth.

Beam, A. (2001). Gracefully Insane. U.S.: Public Affairs.

Bowlby, J. (1969). Attachment and Loss (Vo.1 J): Attachment. New York: Basic.

Bretherton, I. (1992). The Origins of Attachment Theory: John Bowlby and Mary Ainsworth. Developmental Psychology, 28, 759-775.

Brown, D. (1987). The Handbook of Environmental Psychology. New York: John Wiley \& Sons.

Canter, D. \& Canter, S. (1979). Designing for Therapeutic Environments. New York: John Wiley \& Sons.

Carey, J. (1989). Culture as Communication. Boston: Unwin Hyman.

Canter, D. \& Canter, S.(Eds.) (1979). Designing for Therapeutic Environments. New York: John Wiley \& Sons, Ltd.

Centers for Medicare and Medicaid Services. (2013) Community Mental Health Centers. Downloaded at: http;/www.cms.gov/Medicare/Providers-Enrollment-and Certification/CertificationandCompliance/CommunityHealthCenters.html

Charmaz, K. (2006). Constructing Grounded Theory: A practical guide through qualitative analysis. Los Angeles: Sage Publications, Inc.

Chorpita, B. \& Barlow, D. (1998). The Development of Anxiety: The role of control in early environment. Psychological Bulletin, 124 (1),3-21.

Cresswell, J. (2009). Research Design: Qualitative, quantitative, and mixed methods approaches. Los Angeles, Sage Publications, Inc. 
Cresswell, J. (2013). Qualitative Inquiry \& Research Design: Choosing among five approaches. Los Angeles: Sage Publications, Inc.

Csikszentmihayli, M. \& Rochberg-Halton, E. (1981). The Meaning of Things: domestic symbols and the self. Cambridge: Cambridge University Press.

Dalglish, C. (2005). An Age of Transition? Castles and the Scottish Highland estate in the 16th and 17th centuries. Post-Medieval Archaeology, 39(2).

David, T. \& Weinstein, C. (1987). Spaces for Children: The built environment and child development. New York: Plenum Press.

Dear, M., Wilton, R., Gaber, S. \& Takahashi, L. (1997). Seeing People Differently: The sociospatial construction of disability. Environment and Planning D: Society and Space, 15.

Dear, M. \& Wolch, J. (1987). Landscapes of Despair: From Deinstitutionalization to Homelessness. Cambridge: Polity Press.

Department of Health and Senior Services (2013a). Alphabetical Listing of Long Term Care Facilities. Downloaded at: http://health.mo.gov/cgi-bin/nhomes.pl.

Department of Health and Senior Services (2013b). Level of Licensure for Long Term Care Facilities. Downloaded at: http://health.mo.gov/safety/showmelongtermcare/ lvloflic.php.

Department of Health and Senior Services (2013c). Rules of Department of Health and Senior Services: Division 30-Division of Regulation and Licensure, Chapter 86-Residential Care Facilities and Assisted Living Facilities. Downloaded at: http://www.sos.mo.gov/adrules csr/current/19csr/19c30-86.pdf

Department of Health and Senior Services (2013d). Senior and Disability Services: Frequently Asked Questions. Downloaded at: http://health.mo.gov/senior/nursinghomes/faqs.php

Department of Elementary and Secondary Education (2013). Educational Services Provided to Students with Severe Disabilities. Downloaded at: http://dese.mo.gov/se/ep/documents DESEREPORT.pdf

Department of Mental Health (2013). Legal and Advocacy Nursing Home Reform Act Revised 5-3-11. Downloaded at: http://dmh.mo.gov/docs/dd/L8-NursingHomeReformAct5-3-11. pdf.

Després, C. (1991). The Meaning of Home: Literature review and directions for future research and theoretical development. The Journal of Architectural and Planning Research, 8(2).

Dovey, K. (1985). Home and Homelessness. In C. Werner, I. Altman \& D. Oxley (Eds.). Human 
Behavior and Environment: Advances in Theory and Research. Vol.8. New York: Plenum

Dovey, K. (1985). Human Environments. Human Behavior and Environment: Advances in theory research, Vol. 8. Altman, Irwin and Carol M. Werner eds. New York: Plenum Press.

Eggener, K. (1994). Maybeck's Melancholy: Architecture, empathy, empire, and mental illness 1915 Panama-Pacific international exposition. Winterthur Portfolio, 29(4), 211-226.

Ellin, N. (Ed.) (1997). Architecture of Fear. New York: Princeton Architectural Press.

Evans, G. (2001). Environmental Stress and Health. In Baum, A., Revenson, T. \& Singer, J. (Eds.) of Health Psychology. New York: John Wiley \& Sons.

Evans, G. \& Cohen, S. (1987). Environmental Stress. Handbook of Environmental Psychology, , D. \& Altman, I. (Eds.) New York: John Wiley \& Sons.

Evans, G. \& Lepore, S. (1993). Nonauditory effects of noise on children: A critical review. Environments, 10(1).

Evans, G. \& McCoy, J. (1998). When Buildings Don't Work: The role of architecture in human health. Journal of Environmental Psychology, 18.

Fairfield State Hospital website (2013). Downloaded at http://www.fairfieldstatehospital.com/ .html.

Fernandez-Ballesteros, R. (Ed.) (2003). Encyclopedia of Psychological Assessment. Thousand Oaks: Sage Publications.

Flyvbjerg, B. (2011). Case Study. In Denzin, N. \& Lincoln, Y.(Eds.) The Sage Handbook of Research. Los Angeles: Sage Publications, Inc.

Forchuk, C., Nelsonn, G. \& Hall, G. (2006). "It's important to be proud of the place you live in":problems and preferences of psychiatric survivors. Perspectives in Psychiatric Care. (1).

Forty, A. (1986). Objects of Desire: Design and society. London: Thames and Hudson.

Foucault, M. (2006). History of Madness. New York: Roultedge.

Foucault, M. (1994). The Order of Things. New York: Vantage Books.

Foucault, M. (1991). Discipline \& Punish: The birth of the prison. New York: Vantage Books.

Foucault, M. (1965). Madness \& Civilization: A history of insanity in the age of reason. New York: Vantage Books. 
Franck, K. (1980). Phenomenology, positivism and empiricism as research strategies in Behavior research and design. In Zube, E. \& Moore, G. (Eds.). Advances in Environment Behavior and Design. New York: Plenum Publishers.

Goffman, E. (1961). Asylums: Essays on the social situation of mental patients and other . New York: Anchor Books.

Goffman, E. (1963). Stigma: Notes on the management of spoiled identity. New York: Simon \& Schuster, Inc.

Greene County Public Administrator (2013). Mission Statement. http://www.greenecountymo. /public_administrator/.

Groat, L. \& Wang, D. (2002). Architectural Research Methods. Danvers, MA: John Wiley \& Sons.

Gubrium, J. (1997). Living and Dying at Murray Manor. USA: First University Press of Virginia.

Harris, G., Hilton, N. \& Rice, M. (1993). Patients admitted to psychiatric hospital: Presenting problems and resolution at discharge. Canadian Journal of Behavioral Science, 25, $267-$ 285.

Harvard (2013). Virtual tour downloaded at http://www.mclean.harvard.edu/tour/proctor.html.

Heft, H. \& Wohlwill, J. (1987). Environmental Cognition in Children. In Stokols, D. \& Altman, I. Eds.). Handbook of Environmental Psychology. New York: Wiley \& Sons.

Hillier, B. (1996). Space is the Machine: A configurational theory of architecture. United Kingdom: Press Syndicate of the University of Cambridge.

Huber, J. (1995). Centennial essay: Institutional perspectives on sociology. American Journal of Sociology, 101.

Jaroff, M. \& Morse, S. (1983). A proposed framework for the emerging field of architectural research. Laboratory of Architecture and Planning: Massachusetts Institute of Technology.

Koncelik, J. (1976). Designing the Open Nursing Home. Community Development Series, 27. University of Michigan: Dowden, Hutchinson \& Ross.

Lawton, M. (1998). Environment \& Aging: Theory revisited. In Scheidt, R. \& Windley, P. (Eds.). Environment and Aging Theory: A focus on housing. Westport, CT: Greenwood Press.

Lazarus, R. \& Cohen, J. (1977). Environmental Stress. In Altman I. \& Wohlwill, J. (Eds.). 
Human Behavior and Environment. New York: Plenum Press.

Lemke, S. \& Moos, R. (2001). Residential Alternatives for Older Americans. Journal of Experimental Psychology, 71(1).

Ludin, R. (1991). Theories and Systems of Psychology. Lexington, MA: D.C. Heath and Company.

Malnar, J. \& Vodvarka, R. (2004). Sensory Design. Minneapolis: University of Minnesota Press.

Markus, T. (1993). Buildings and Power. New York: Rutledge.

Mathews, G. (2011). Personal Interview.

Maxwell, J. (2013). Qualitative Research Design: An interactive approach. Los Angeles: Sage Publications, Inc.

Missouri Department of Social Services. Early Childhood Grants \& Resources. Downloaded at http://dss.mo.gov/cd/early/

McLean Hospital home page. About Us. Downloaded at: http://www.mclean.harvard.edu/about/

McLean Hospital press release (October 21, 2002). McLean Hospital Tapped for National Register of Historic Places. Downloaded at: http://www.mclean.harvard.edu/news/ press/current.php?id=30.

Moore, G. (1987). The Physical Environment and Cognitive Development in Child-Care Centers. In Weinstein, C. \& David, T. (Eds.) Spaces for Children: The built environment and child development. New York: Springer.

Morgan, G. (Ed.). (1983). Beyond Method: Strategies for Social Research. Beverly Hills: Sage Publications.

Mushkatel, A., Guhathakurta, S., Thompson, J., Thomas, K. \& Francsak, M. (2009). Housing choice, outcomes, and neighborhood characteristics in housing programs for individuals with a serious illness: Analysis of a Phoenix survey of individuals with a serious mental illness. Public Administration Quarterly, Winter, 481-519.

Nesbitt, K. (1996). Theorizing a New Agenda for Architecture: An anthology of architectural theory 1965-1995. New York: Princeton Architectural Press.

Newman, S. \& Goldman, H. (2009). Housing policy for persons with severe mental illness. The Policies Studies Journal, 37(2).

Norman, D. (1973). The Psychology of Everyday Things. New York: Basic. 
O'Connell, M., Rosenheck, R., Kasprow, W., Frisman, L. (2006). An examination of fulfilled housing preferences and quality of life among homeless persons with mental illness and/or substance abuse disorders. The Journal of Behavioral Health Services Research, $33(3)$.

Osburn, J. (1998). An Overview of Social Role Valorization Theory. The International Social Role Valorisation Journal/La revue internationale de la Valorisation des roles sociaux, $3(1), 7-12$.

Owens, M. (1982). My 60 Years in Humansville. Self-published, 1982.

Patton, M. (2001). Qualitative Research and Evaluation Methods. Thousand Oaks: Sage Publications.

Porteous, J. (1977). Environment \& Behavior: Planning and everyday urban life. Boston, Addison-Wesley.

Richards, L. \& Morse, J. (2013). README FIRST FOR A User's Guide to Qualitative Methods, Third Edition. Los Angeles: Sage Publications.

Robinson, J. (2006). Institution and Home: Architecture as a cultural medium. Amsterdam: Techne Press.

Rothman, D. (1971). The Discovery of the Asylum: Social order and disorder in the new republic. Boston: Little, Brown \& Company.

Rybczynski, W. (1986). Home: A short history of an idea. New York: Penguin Books.

Saldaña, J. (2013). The Coding Manual for Qualitative Researchers. Los Angeles: Sage Publications, Inc.

Satariano, W. (2006). Epidemiology of Aging: An ecological approach. Boston: Jones and Bartlett Publishers.

Schwarz, B. (1996). Nursing Home Design: Consequences of employing the medical model. New York: Garland Publishing, Inc.

Scull, A. (Ed.) (1977). Decarceration: Community treatment and the deviant-a radical view. Englewood Cliff, NJ: Prentiss Hall.

Scull, A. (1979). Museums of Madness: the social organization of insanity in nineteenth-century England. London: Allen Lane.

Scull, A. (2013). The Asylum as Utopia (Psychology Revivals). W.A.F. Brown and the midnineteenth century consolidation of psychiatry. London: Rutledge.

Seamon, D. (2000). A way of seeing people and place: Phenomenology in Environment- 
Behavior research. In Wapner, S., Demick, J., Yamamoto, C., \& Minami, H. (Eds.). Theoretical Perspectives in Environment -Behavior Research. New York: Plenum Publishers.

Seligman, M., Walker, E. \& Rosenthan, D. (2000). Failure to escape from traumatic shock. Journal of Experimental Psychology, 71(1).

Smith, N. (1996). The New Urban Frontier. New York: Rutledge.

Spivack, M. (1984). Institutional Settings: An environmental design approach. New York: Human Services Press.

Sroufe, L. (2005). Attachment and Development: A prospective, longitudinal study from birth to adulthood. Attachment \& Human Development. 7(4).

Sundstrom, E. \& Sundstrom, M. (1986). Work Places: the psychology of the physical environment in offices and factories. New York: Cambridge University Press.

Sutton, S. (1997). Creating Landscapes of Safety. In Ellin, N. (Ed.) Architecture of Fear. New York: Princeton Architectural Press.

Szasz, T. (1970). The Manufacture of Madness: A comparative study of the inquisition and the mental health movement. New York: Syracuse University Press.

Tsai, J., Bond, G., Saylers, M., Godfrey, J. \& Davis, K. (2010). Housing preferences and choices among adults with mental illness and substance abuse disorders: A qualitative study. Mental Health Journal, 46(4), 381-388.

Tsui, E. (1999). Evolutionary Architecture: Nature as a basis for design. Danvers, MA: John Wiley \& Sons.

Thoits, P. (1995). Stress, Coping, and Social Support Processes: Where are we? What next? Journal of Health and Social Behavior (Extra Issue).

von Eckartsberg, R. (1998). Introducing existential-phenomenological psychology. In Valle, R. (Ed.), Phenomenological inquiry in psychology: Existential and transpersonal dimensions Science and Qualitative Research. New York: Plenum Press.

Wachs, T. \& Evans, G. (2009). Chaos in Context. In Evans, G. \& Wachs T. (Eds.). Chaos and Its Influence on Children's Development: An ecological perspective. Washington, D.C.: American Psychological Association.

Warren, R. \& Bell, P. (2000). An exploratory investigation into the housing preferences of consumers of mental health services. Australian and New Zealand Journal of Mental health Nursing, 9, 195-202.

Wohlwill, J. (1984). Psychology and the Environmental Disciplines. In Bornstein, M. (Ed.). 
Psychology and Its Allied Disciplines: Psychology and the social sciences. New Jersey: Lawrence Earlbaum Associates, Inc.

Wohlwill, J. \& Heft, H. (1991). The Physical Environment and the Development of the Child. In Stokols, D. \& Altman, I. (Eds.). Handbook of Environmental Psychology. Malabar, FL: Krieger Publishing Company.

Woltman, E. \& Whitley, R. (2010). Shared decision making in public mental health care: perspectives from consumers living with severe mental illness. Psychiatric Rehabilitation Journal, 34(1), 29-36.

Yanni, C. (2007). The Architecture of Madness: Insane asylums in the United States. Minneapolis: Minnesota University Press.

Yin, R. (2011). Qualitative Research From Start to Finish. New York: The Guilford Press. 